\title{
¿FÍBULAS PENINSULARES DE CODO «SÍCULAS» O DE TIPO «MONACHIL»? NOVEDADESY REVISIÓN
}

\author{
PENINSULAR FIBULAE: ELBOW “SÍCULAS” OR TYPE “MONACHIL”? NEWS AND REVISION
}

JAVIER CARRASCO RUS

Universidad de Granada

JUAN A. PACHÓN ROMERO

Universidad de Granada

IGNACIO MONTERO RUIZ

Consejo Superior de Investigaciones Cientificas

ALFREDO GONZÁLEZ PRATS

Universidad de Alicante

JESÚS GÁMIZ JIMÉNEZ

Universidad de Granada

\section{INTRODUCCIÓN}

En las nomenclaturas tipológicas que hemos aportado sobre las más antiguas fíbulas de codo peninsulares, sin intención de enrarecer a priori la visión global que pudiésemos dar de ellas, hemos intentado simplificarlas y englobarlas en dos grandes grupos. En primer lugar, las que se integrarían en el denominado grupo Huelva, conocido desde los trabajos de Almagro Basch (Almagro, 1940a, 1940b, 1952, 1957, 1957-58, 1958, 1966 y 1975), aunque más ampliamente sistematizado y consolidado por nuestras propias investigaciones (Carrasco et alii, 1985, 1987, 1999, 2002, 2004, 2005, 2006a, 2006b, 2006c, 2012). El segundo grupo, más extenso, peor caracterizado y objeto de múltiples confusiones taxonómicas bajo el calificativo de sículo, englobaría grosso modo, sin mayor particularización, al menos cinco subgrupos fibulares de variadas morfologías, aunque entre algunos de ellos puedan -en origen o desarrollos- existir posibles conexiones y similitudes. En primer lugar, estarían las denominadas lisas o, sensu stricto, sículas de Almagro Basch; en segundo lugar, las denominadas de codo y puente descentrado, en algún caso -y para nosotros- las mal llamadas de arco o de violín. Las ad occhio de bucle central, sustitutivo del codo, formarían el tercer grupo. Las de pivote de codo macizado, aletas laterales en el puente y gozne sustitutivo del muelle, constituirían el cuarto grupo. Por último, el quinto grupo, quizás el más escaso y problemático, integrado por las de codo con antenas.

En general, conforman un extenso y heterogéneo grupo, peor caracterizado que el constituido por el denominado Huelva. En su globalidad, todo el conjunto fibular, lisas y con molduraciones, ocuparían un espacio cronológico aproximado entre los siglos XIIIIX a.C. En estos cinco o seis siglos de vigencia, es lógico que algunos de los tipos descritos conviviesen entre ellos y que otros, en su prolongado devenir, provocasen nuevas apariciones y desapariciones. En definitiva, se pueden admitir desarrollos evolutivos, coetaneidades, superposiciones, etc. No siendo aceptable un estudio conjunto de ellas, en el que se confundan sus características morfológicas y cronológicas, en aras de intereses particularizados o fruto de un más general desconocimiento.

En esta investigación nos centraremos en el gran grupo sículo, exclusivamente en el estudio de las fíbulas de codo peninsulares, que entrarían en un primer subgrupo que en diferentes trabajos previos hemos denominado tipo Monachil. Para su estudio intentaremos adecuar un modelo que, en cierta forma, como avanzábamos en el análisis de las del grupo Huelva, se base en secuencias estratigráficas, hallazgos cerrados, dataciones absolutas, aspectos tipológicos, composiciones metalográficas, etc. ${ }^{1}$ Aunque, para el caso del tipo de fíbulas que en esta ocasión nos ocupa, difícilmente se

\footnotetext{
1. En una investigación reciente (Vilaça et alii, 2012) se alude a que nuestros argumentos, para fechar las fíbulas de codo tipo Huelva, son coyunturales (sólo análisis de composición de metales) y no tipológicos. Cuestión en la que no entraremos, ni aclararemos, ya que estos comentarios merecerían una crítica detallada que no viene al caso. Al respecto, sólo indicar que no sabemos bien si estos autores solo yerran, no interpretan adecuadamente, no han leído suficientemente o, en definitiva, desconocen algunos de los artículos que citan. Por lo menos, dicha publicación no lo refleja en sus argumentaciones.
} 
les pueda aplicar - en la mayoría de los casos- la totalidad de estos parámetros, por lo que resulta difícil definir seriaciones evolutivas tipológicas y cronológicas. De todos modos, la falta de gran parte de los contextos arqueológicos asociados a los hallazgos impide, de momento, hacer una auténtica clasificación de suficiente valor cronológico, al menos antes de plantear otras argumentaciones de interés que podrán arrojar suficientes elementos de juicio en este sentido. Así, los hallazgos secuenciados del Cerro de la Mora (Moraleda de Zafayona, Granada), de igual forma que para el estudio de las del grupo Huelva constituyó el ejemplar localizado en su anejo del Cerro de la Miel, son los únicos que pueden aportar datos relevantes.

Por último, resaltar que presentamos un conjunto de fíbulas de gran interés, algunas de ellas inéditas, entre las que no incluimos las únicas secuenciadas del Cerro de la Mora. No considerarlas, aunque estén documentadas, se debe primero a la falta de análisis metalográficos, que aún no ha sido posible por su mal estado de conservación. En segundo lugar, porque su incorporación implicaría la presentación de otros registros broncíneos y cerámicos de apoyo, que sobrepasarían el ámbito físico de este trabajo. De ellas, solamente ofreceremos algunas referencias y sugerencias crono-tipológicas.

\section{FÍBULAS SÍCULAS DE TIPO MONACHIL}

Sin demasiadas dudas, podemos argumentar que la denominación sículas, para definir o caracterizar las fíbulas de codo peninsulares con puentes de brazos sin moldurar, tiene su origen en los primeros estudios que Almagro Basch realizó sobre el ejemplar aparecido entre los bronces del depósito de la Ría de Huelva. Así, en uno de sus primeros trabajos (Almagro, 1940a, 138), consideraba que las fíbulas eran los únicos objetos del depósito que reflejaban relaciones directas con el Mediterráneo Central, haciendo derivar el tipo, ya más evolucionado por su decoración, de las formas sículas tardías de Cassibile, con una fecha no anterior al 750 a.C. Opinaba que «los tipos sicilianos han hecho nacer, desde luego, los modelos españoles, del que es el más antiguo ejemplar el de Huelva, pero no el único, y de ninguna manera de la misma época que sus precedentes sicilianos. Aclimatado en España el tipo, perduró evolucionando, siendo un caso más del conservadurismo extremo de nuestra Península». Pero fue sustituyendo, progresivamente, los paralelos del Mediterráneo Central por los de Chipre y Palestina, para justificar la presencia de estas fíbulas en la Península Ibérica, en relación con el comercio fenicio-chipriota (Almagro, 1940b, 3). Este trabajo muestra cómo los paralelos exógenos, que cotejó en primer lugar para estas fíbulas, cambiaron de modo progresivo, a medida que avanzaba en sus investigaciones.

En uno de sus últimos trabajos sobre el tema (Almagro, 1966, 182 ss.) diferenciaba nítidamente en el depósito onubense, con orígenes independientes, dos modelos de fíbulas de «arco acodado»: «un modelo de claro origen chipriota con los arcos aplanados y agallonados y otro producido en Sicilia, con los arcos redondos y amorcillados con o sin decoración incisa y geométrica» (Almagro, 1966, 183). Ambos tipos representados entre los bronces de la Ría y que, según Almagro, «no es posible asegurar qué tipo fue el primero ni cual tuvo mayor uso y dispersión, aunque todo parece inclinarse a favor del que hemos llamado fibula "tipo Huelva"» (Almagro, 1966, 183). Precisando, indica que «puede considerarse sícula la fibula de arco acodado con sus brazos algo amorcillados, es decir, más gruesos en su centro y más delgados hacia su extremo, tipo que no parece se divulgó tanto entre nosotros» (Almagro, 1966, 184).

Con estos sintéticos textos queremos significar que, si Almagro en un primer momento de sus investigaciones cotejó globalmente las fíbulas de la Ría, principalmente con ejemplares sicilianos, de los que tomó la denominación generalizada de sícula, posteriormente las diferenció en dos tipos o grupos: sículo y chipriota o tipo Huelva, atendiendo a sus supuestos orígenes en alguna de esas islas mediterráneas. Casi siempre bajo la óptica de modelos difusionistas y paralelos descontextualizados, muy propios de la época.

Las diferencias que se han establecido entre ambos conjuntos vendrían marcadas por el distinto tratamiento ornamental que se da al puente de la fíbula: en el segundo de los casos, la decoración se circunscribe a una serie de fajas y abultamientos, delimitados por unas incisiones más o menos profundas, que se reparten en cada uno de los brazos; en el primero, apreciamos una técnica decorativa diferente, gracias al tratamiento de la incisión burilada, que reúne, tanto los motivos lineales paralelos, como los geométricos más complejos de rombos, zigzags, etc. Las sículas presentarían, casi siempre, una mayor uniformidad de la sección en cada brazo del puente. Las secciones de las distintas partes de la fíbula pueden ser variables, pero lo común es que sean circulares, oblongas, lenticulares, de fino segmento de círculo, etc. Aunque en algunos casos encontremos mayor variabilidad, debido a los elementos decorativos que aparecen en el puente.

Estas consideraciones generales introductorias que hemos efectuado no tendrían sentido, por su obviedad, en cualquier otra línea de investigación; pero aún pueden considerarse necesarias, como punto de partida para otro tipo de elucubraciones más específicas. En tal sentido, sigue existiendo, en gran parte de los investigadores peninsulares que se han aproximado a ellas, un gran desconocimiento en el tema de las fíbulas antiguas de codo peninsulares. Habiéndolas globalizado, en muchos casos, bajo el paradigma de lo sículo y, en otros, confundiendo los tipos. Subyaciendo, en todo caso, una manipulación interesada en relación con sus secuencias y cronologías.

De las diez fíbulas de codo que Almagro estudió procedentes de la Ría, nueve -entre completas y 
fragmentos- eran del tipo Huelva; mientras que un resto del brazo de un puente correspondería a la famosa fíbula sícula, que tanta importancia tuvo en sus trabajos iniciales, al establecer las relaciones centromediterráneas del depósito. A partir de estas investigaciones pioneras de Almagro Basch y en un rápido recorrido, respecto de otras nacionales realizadas sobre este tipo de fíbulas, tradicionalmente denominadas sículas, hemos de hacer referencia sucinta a ciertos trabajos que, en cierto modo y en algún aspecto, las han tratado o interpretado, aunque no muy correctamente, incluyéndonos nosotros mismos.

Así, a finales de los años setenta nos aproximábamos al mundo de las fíbulas de codo (Carrasco et alii, 1980) con el estudio del caso de Cerro Alcalá, procedente de una incineración en urna que había aparecido en labores agrícolas rutinarias. Nuestro trabajo, algo precipitado, lo relacionaba directamente con el ejemplar procedente de Cerro de la Encina de Monachil (Granada) y con el registro cerámico de similares enclaves andaluces y levantinos. Las cronologías peninsulares que ofertábamos estaban en relación con las aportadas, básicamente, para las de la Ría de Huelva, San Román de Hornija, etc. Es decir, lo único que entonces se conocía, junto con las tradicionales y problemáticas dataciones de Megiddo Va y Pantalica II. Pero introdujimos un matiz diferenciador, más localista, cuando cotejamos la decoración que presentaban los brazos de su puente con similares ornatos de brazaletes, anillas de hachas de aletas, etc. Un aspecto en el que se criticaron nuestras comparaciones y similitudes expuestas, respecto de las decoraciones que ostentaban los brazaletes de Berzocana y su cronología entre los siglos XII-X a.C. En definitiva, utilizamos en el análisis argumentos propios de la época, apuntando ciertos matices indigenistas para su decoración que aún no hemos desechado; pero tampoco confundimos esta fíbula, ni la entroncamos con ningún otro tipo distorsionante, ni la relacionamos con paralelos exóticos peor contextualizados.

Siete años después, en un trabajo realizado sobre el yacimiento madrileño de Perales del Río, C. Blasco, al estudiar una fíbula «ad occhio» procedente de un «fondo» (posible silo), efectuó una serie de reflexiones crono-culturales y tipológicas que, escuetamente, consideramos necesario resaltar (Blasco, 1987). Más que nada, y extrañamente, por la incidencia que han tenido en investigaciones recientes; aunque esta pieza no entraría en la tipología del grupo de fíbulas objeto de este estudio. Así, C. Blasco, siguiendo el antiguo esquema de Almagro, consideró dos grupos peninsulares de fíbulas de codo: «sirio-chipriotas» y «sículas»; en estas últimas, incluía las de tipo «ad occhio», de arco descentrado, lisas de codo centrado, etc. Todas, llegadas desde ambientes mediterráneos próximos y lejanos. Al respecto, pueden ser significativas y esclarecedoras algunas de las «rutas» que la propia Blasco señalaba y describía. Indicaba, ante la duda sobre si las fíbulas peninsulares eran productos locales o de importación directa, que «sí puede apuntarse ya que a través de los tipos de fibulas de codo existentes en la Península se vislumbra un doble circuito de comercio mediterráneo, durante los siglos Xy IX a.C.; justo antes del gran auge fenicio. Por una parte, existe una gran ruta realizada, sobre todo, por grupos procedentes del Mediterráneo oriental que, a partir de Sicilia, actúa principalmente en las costas meridionales del Mediterráneo occidental, incluidas las de la Península Ibérica, llegando a la fachada atlántica hasta las costas del canal de la Mancha. A lo largo de toda esta amplia zona costera llegan elementos materiales, principalmente metales, como es el caso de las fíbulas de codo, tanto de inspiración sirio chipriota, como sícula» (Blasco, 1987, 27). Aunque no sabemos, a ciencia cierta, si esta «ruta original» estaba inspirada en los trabajos de Coffyn o se debía a la propia autora; sí pudimos intuir que Sicilia, al parecer, constituyó al final de la Prehistoria un puerto franco, a partir del cual se distribuía este tipo de fíbulas y, así, a través de los Alpes y Francia, se llegaría al Canal de la Mancha $\mathrm{y}$, desde allí, por un «tráfico atlántico», alcanzarían la Meseta y el suroeste las fíbulas «sirio-chipriotas». Por contra, las sículas llegarían al sureste peninsular por un comercio directo desde Sicilia.

En torno a esto, sólo indicaremos que no hay ni una sola fíbula de las que podamos denominar «tipo Huelva», o que Blasco incluya en su grupo «sirio-chipriota», en Sicilia; a no ser los ejemplares chipriotas tardíos que los mismos especialistas italianos, como es el caso de F. Lo Schiavo, hacen derivar de los escasos ejemplares peninsulares documentados. Algo parecido puede decirse del ámbito atlántico, donde tampoco existen. Nos queda la garantía, si esta autora hubiese conocido entonces (ya se habían publicado -entre otros- los ejemplares del Cerro de los Infantes, Cerro de la Mora, etc.) la dispersión real de las fíbulas de codo en la Península, de que no hubiese llegado a la siguiente conclusión: 'puede decirse que la mitad oriental peninsular parece no haber incorporado las fíbulas de codo gallonadas de inspiración sirio chipriota, pero posee, en cambio, piezas de marcado ambiente sículo» (Blasco, 1987, 27). También son interesantes algunas de sus observaciones tipológicas que, aunque no propiamente suyas, sí acepta y matiza. Por ejemplo, el hecho de admitir que fíbulas lisas, como la de Mansilla de las Mulas o la de Monachil, pueden ser derivaciones tardías de «ejemplares más característicos, con gallones, en un proceso, como acontece a otros ejemplares metálicos, tendente a la simplificación» (Blasco, 1987, 24). Es decir, que las fíbulas «sirio chipriotas», en último caso, darían lugar a las lisas «sículas»y, a partir de aquí, eclosionarían en las fíbulas tardías estudiadas por Cabré/Morán, procedentes de la Meseta (s.c.).

Finalmente, algunos años después, un nuevo estudio sobre los bronces de la Ría (Ruiz Gálvez, 1995) daba un tratamiento bastante insuficiente a la fíbula lisa del depósito; no solo en el aspecto tipológico y gráfico (Fig. 2: 3), sino también en la contextualización. 
Este rápido y sintético recorrido es ilustrativo de cómo algunos autores han referenciado estas fíbulas lisas de forma controvertida y algo sesgada, a partir, más que nada, de los ejemplares de la Ría y Cerro Alcalá. Por supuesto que no han sido las únicas referencias destacables, pero sí han marcado ciertas líneas deliberativas que no han dejado de utilizarse:

Así, M. Torres (2002), en una reciente obra de síntesis, bajo un epígrafe titulado «Las fibulas de codo de tipo Cassibile II-III», indica siguiendo a Almagro Basch y a Ruiz-Gálvez, que «En el depósito de la Ría de Huelva, junto a las fíbulas que toman su nombre del mismo, se documentó igualmente la existencia de un ejemplar de fíbula de clara procedencia siciliana y que casi con seguridad fue importada de esta isla». Deduciendo, a continuación, que «La importancia de estas piezas radica en que, seguramente, son de las que derivarán las fibulas de tipo Ría de Huelva, que tanta difusión tendrán en el Sudoeste peninsular y, en general, en toda la fachada atlántica» (Torres, 2002, 171). La lectura de estos textos causa cierta sorpresa, pues habla en plural de estas fíbulas, cuando en realidad hay una sola problemática, como recientemente hemos comprobado (Carrasco et alii, 2012). De igual forma, también desconocemos esa gran difusión fibular a la que alude Torres por el Sudoeste y fachada atlántica, sin indicar el tipo de espécimen.

Un último trabajo del mismo especialista (Torres, 2012) vuelve a plantear afirmaciones, cuanto menos controvertidas y, desde luego, sin el suficiente rigor. Señala las fíbulas como recurrentes objetos de representación en las estelas extremeñas, pero sin explicitar de qué fíbulas se trata. De su texto se intuye que debe referirse a las del tipo Huelva, que son las que le interesan para citar una serie de artículos relativos al hallazgo broncíneo de la ría onubense, pero obviando en qué estelas aparecen representadas; todo, para afirmar como referente general de conocimiento que este tipo de fíbulas surgió como consecuencia de la llegada a la Península Ibérica de ejemplares sículos, de los que evolucionarían posteriormente en el tipo Ría de Huelva (Torres, 2012, 462). Sin embargo, después de citar a Birminghan sin aclarar por qué y omitir de dónde obtiene la referencia sobre las concentraciones de este tipo de fíbulas en la Península, junto a otras disquisiciones tipológicas sobre los ejemplares orientales, insiste -sin mayor documentación-sobre el origen peninsular de estas fíbulas. A continuación, entre datos de hallazgos extremeños poco precisos y la afirmación de la mayor antigüedad de la fíbula de arco descentrado del Cerro de La Muralla de Alcántara, sin mayor argumentación científica señala seis fíbulas en Extremadura; aunque olvida que serían nueve. Siempre que contabilicemos la mejor adaptada al modelo, presente en las estelas del Sudoeste, que es la del tipo Encomi de «Pajares» (Villanueva de La Vera, Cáceres), ya descrita equivocadamente como de «arco» (Celestino, 2001, 205, Fig. 51), junto con las dos de tipo Monachil de Los Concejiles de Lobón.
Entre lo más trascendente, tras repetir y argumentar sobre los modelos orientales, que ya expusimos hace años al igual que A. Mederos (1996), y sin citar sus fuentes de información, indica que estas fíbulas de ignoto tipo son contemporáneas del vaso de Berzocana, sorprendiendo el uso contrario que hace del mismo argumento que constituyera el principal apoyo para las críticas que se nos efectuó hace más de treinta años, cuando relacionamos las decoraciones de los brazaletes de Berzocana con las de la fíbula giennense de tipo Monachil de Cerro Alcalá. Aunque quizás sea más relevante su 'descubrimiento' de la cronología de las fibulas de la Ría en el s. X a.C., planteando una problemática cronológica de difícil solución. Así, primero admite que las fibulas tipo Huelva son de origen sículo, pero luego les adjudica un origen peninsular para incluso llegar a «las costas de Fenicia e Israel» (Torres, 2012, 464); aunque, igualmente, había expuesto con anterioridad que «estas piezas alcanzan también el Mediterráneo oriental en un momento que se puede fijar entre mediados del siglo XI y mediados del X a.C.» (Torres, 2012, 463). Cabría preguntarse, en primer lugar, de qué modelos sículos derivarían los tipos peninsulares; en segundo lugar, qué cronología tienen; en tercer lugar, si la fecha del s. X se refiere al depósito general de la Ría o a sus fíbulas; en cuarto lugar, qué relación tiene Amathus 523, Ayia Irini, la fíbula chipriota del MAN, Megiddo Va, etc. con los casos de la Ría. No parece que M. Torres haya desentrañado bien esas relaciones, pese a que ya lo expusimos hace casi una década (Carrasco y Pachón, 2006a y 2006c). Pero, además y en la actualidad, Megiddo Va, lo mismo que Achziv y el Bronce Final de la Ría de Huelva, paralelo al Hierro II oriental, se fechan, aunque no estemos muy de acuerdo en el caso de las fíbulas españolas, hacia la mitad del siglo X a.C. (Bruins et alii, 2011). Por ello, resulta complicado conciliar la presunta llegada de las sículas a la Península, el tiempo de su reconversión en el tipo Huelva y su exportación a Próximo Oriente, tal como ha sido expuesto por M. Torres.

Cuestiones, entre otras similares de este autor, sobre las que no profundizaremos, pues en parte y sucintamente ya se han tratado en una muy reciente investigación (Carrasco et alii, 2012). De igual forma, eludiremos otros trabajos (Celestino, 2001 y 2008) de relativa contribución a la investigación que proponemos, que también referenciamos parcialmente en el estudio citado.

Por nuestra parte, los diversos trabajos realizados a partir de mediados de los años ochenta (Carrasco et alii, 1985), sobre las antiguas fíbulas de codo peninsulares, se han centrado en las del tipo Huelva. Aislándolas del resto de las denominadas fíbulas de codo, que -en cierto modo- entrarían en el grupo de las llamadas lisas o de tipo sículo, también denominadas por nosotros de 'tipo Monachil', en reconocimiento al ejemplar estudiado por W. Schüle, procedente del Cerro de la Encina de Monachil, Granada (Schüle, 1969). Es un grupo fibular complejo, que como ya se 
ha indicado acogería formas bien diferenciadas entre las documentadas en la Península. Nunca las hemos relacionado, por origen o tipología, con las del tipo Huelva, pues no se asemejan morfométricamente con él. De igual forma, tampoco las hemos considerado, a partir de modelos acomodaticios poco contrastados, como importaciones sensu stricto desde otros ámbitos mediterráneos poco precisos. El simple cotejo del tipo estudiado, con sus supuestos ancestros en estas geografías, nos hace desistir de ello, porque, desde esta perspectiva, se crea en su investigación una problemática de difícil solución, que a priori nunca condicionaremos, si no es imprescindible y evidente, a impuestos y manipulados paralelismos exógenos que justifiquen su original presencia en la Península.

\section{EL REGISTRO ARQUEOLÓGICO EN LA PENÍNSULA IBÉRICA. DISPERSIÓN REGIO- NAL (Fig. 1)}

Este apartado estudia la dispersión regional de estas fíbulas en la Península, ajustando sin ninguna especulación, o chauvinismo, su aparición exclusiva en estos ámbitos, por lo que tampoco consideramos determinante su registro geográfico vigente; aunque los datos que en la actualidad conocemos son suficientemente esclarecedores y contrastados, remitiéndonos a ellos en esta investigación.

\section{III.A. ANDALUCÍA OCCIDENTAL}

En el registro vigente, dos son las fíbulas que proceden de este ámbito andaluz; siendo posible que alguna de ellas, o incluso ambas, no tengan un origen concreto en dicha geografía.

1. Ría de Huelva. En una investigación reciente hemos comentado la problemática de este fragmento de fíbula, que tanta importancia tuvo en los trabajos pioneros de Almagro Basch (Carrasco et alii, 2012). En relación con la adscripción de esta fíbula lisa al tipo Cassibile, indicábamos que se debía, más que nada, al supuesto asimetrismo de su puente, basado en la hipotética reconstitución gráfica realizada en su momento (Almagro, 1957, 10, Fig.1). Reconstrucción que nunca nos ha parecido correcta, como tampoco que la fíbula pudiese considerarse en el origen del resto de tipo Huelva del depósito. La configuración del fragmento, con el brazo izquierdo del puente casi completo, junto a restos de la mortaja y el codo, de unos 3,4 cm de longitud, admitiría otro tipo de restitución más adecuada y menos imaginativa, con un alzado seudotriangular y codo más o menos centrado, similar a otras conocidas: en especial, la que posteriormente señalaremos del Cerro de las Agujetas. Almagro Basch (1957), en su reconstrucción inicial, dispuso el fragmento de forma más vertical, de manera bastante correcta, añadiéndole el brazo derecho con más inclinación y mayores

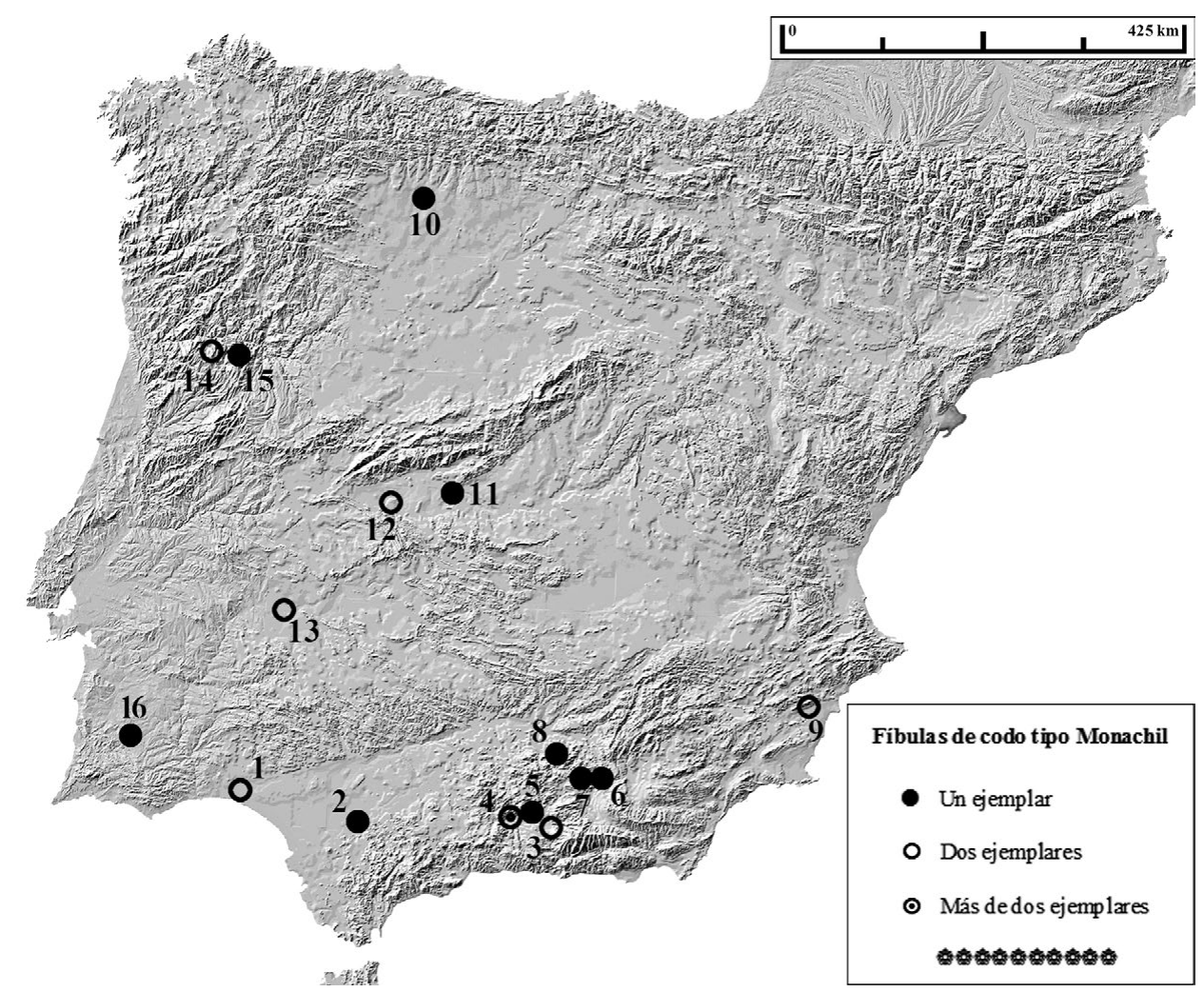

Figura 1: Fíbulas 'sículas' de tipo Monachil: Distribución de hallazgos. Ría de Huelva (1); El Coronil(2); Monachil (3); Cerro de la Mora (4); Pinos Puente (5); Canto Tortoso (6); Las Muelas (7), Cerro Alcalá (8), Peña Negra (9); Mansilla de Mulas (10); Talavera la Vieja (11); La Muralla (12); Los Concejiles (13); Mondim da Beira (14); Monte Airoso (15) y Nossa Senhora da Cola (16). 
dimensiones, junto con una aguja relativamente plana (Fig. 2: 1). En una posterior revisión, el brazo lo inclinaba aún más $\mathrm{y}$, a su vez, la reconstrucción del derecho lo aplanaba, a partir su mayor inflexión respecto de una aguja totalmente plana (Fig. 2: 2) (Almagro, 1958). Todo, tendente a reconstruir una fíbula de codo plenamente asimétrica, al estilo de algunas de las necrópolis sicilianas de Cassibile. A partir de estos estudios que Almagro documentó exhaustivamente, junto con ejemplares de muy diversa tipología, no solo sicilianos, sino chipriotas e incluso micénicos, elaboró un modelo de fíbula asimétrica que se ha mantenido a lo largo de los años y que, en cierta forma, condicionó el de las de tipo Huelva.
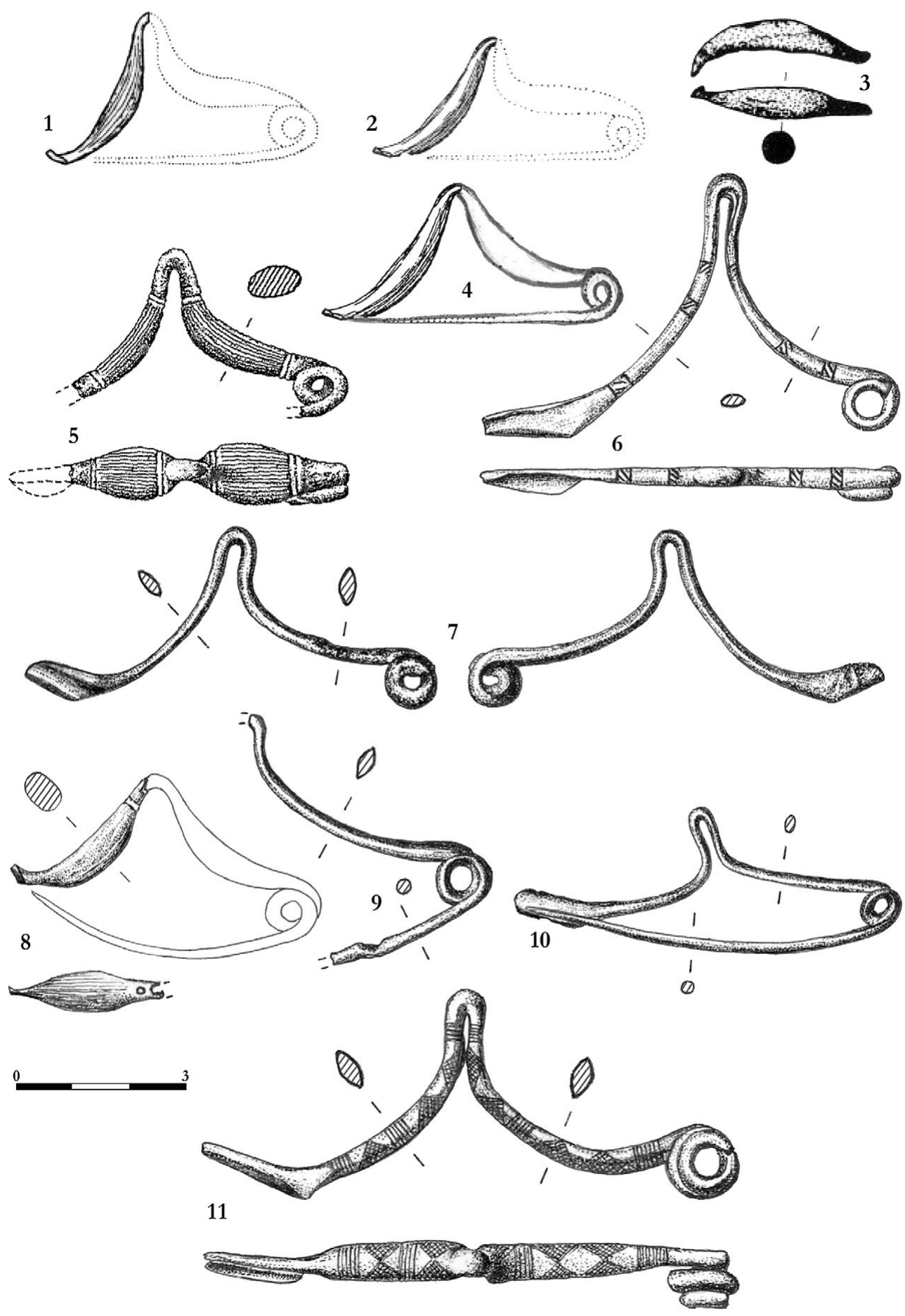

Figura 2: Fíbulas ‘sículas’ de tipo Monachil. Andalucía: Ría de Huelva [según M. Almagro (1-2), Mª L. Ruiz-Gálvez (3) y J. Carrasco (4)]; 5. El Coronil (Sevilla); 6-7. Cerro de la Encina, Monachil (Granada); 8. Las Agujetas, Pinos Puente (Granada); 9. Canto Tortoso, Gorafe (Granada); 10. Las Muelas, Alamedilla (Granada); 11. Cerro Alcalá, Mancha Real/Torres (Jaén). 
Años más tarde, en un nuevo estudio sobre los bronces de la Ría, M ${ }^{a}$ L. Ruiz-Gálvez, que se arriesgó a revisar los trabajos de Almagro Basch sobre el depósito onubense, describe esta fíbula a partir de una insuficiente documentación (Fig. 2:3), como «del arco aplastados, sin decoración. Conserva la aguja, el muelle y el Charnela: No conservada» (Ruiz-Gálvez, $\left.1995,223, n^{\circ} 27\right)$. Aunque, posteriormente, indica que no tiene mortaja ni aguja. Descripción que no necesita comentario, al igual que buena parte del resto de afirmaciones y argumentaciones realizadas por la autora sobre el conjunto de las fíbulas de la Ría.

En nuestra opinión, como ya se ha expuesto en otro lugar (Carrasco et alii, 2012), el brazo del puente conservado, con restos de codo y mortaja, se correspondería con una fíbula de pequeñas dimensiones, codo centrado y decoración de finas líneas incisas paralelas a los brazos (Fig. 2: 4). Fundida en bronce binario, muestra un porcentaje medio/alto $(13,61 \%)$ de estaño (Sn) y una morfometría muy similar, entre otras, a los ejemplares de El Coronil y Cerro de las Agujetas, etc. $\mathrm{Su}$ cronología, como en otro apartado argumentaremos, debe ser relativamente tardía entre los ejemplares que componen este grupo.

2. El Coronil (Sevilla) (Fig. 2: 5). De procedencia desconocida, se localiza en una colección privada de esta localidad sevillana una fíbula del tipo que estudiamos. M. M. Ruiz Delgado la referenció parcialmente en su Tesis Doctoral (Ruiz, 1989), aunque nunca llegó a publicar su dibujo. Posteriormente, un trabajo póstumo (Ruiz et alii, 1991) realizó, desde el punto de vista metalográfico, un breve estudio con algunas consideraciones de orden cronológico y tipológico que, por sus características, pensamos que ya no fueron ultimadas por él, aunque se hiciera bajo el influjo parcial de su trabajo doctoral. Algunas referencias sobre la fíbula, así como su dibujo definitivo y novedoso, las expusimos en otro sitio (Carrasco et alii, 1999).

La fibula se presenta incompleta, faltándole el pie (mortaja) y la aguja. El codo, abierto, es liso y aparece centrado en el puente, presentando brazos de sección oblonga, decorados en su parte superior por dos grupos de incisiones verticales, que enmarcan amplias fajas centrales con finas incisiones longitudinales y paralelas. Sus dimensiones actuales son: longitud total, $4,7 \mathrm{~cm}$; altura, $2,5 \mathrm{~cm}$ y sección máxima en la parte central del brazo derecho, $0,9 \mathrm{~cm}$. Fue catalogada por M. M. Ruiz en su grupo I.lb, caracterizado por el puente masivo, perfil fusiforme y sección ovalada, asimilándola con los ejemplares de la Ría de Huelva (Ruiz, 1989, 51). A pesar de la opinión de M. M. Ruiz, que pudimos contrastar con él, es una fíbula que siempre hemos sido reticentes a incluir en el tipo Huelva (Carrasco y Pachón, 2006b), pues no presenta molduraciones en los brazos constitutivos del puente; aunque sus fajas decorativas incisas guardan ciertos patrones similares que, quizás, evidencien algún desarrollo tardío colateral del tipo onubense. Junto a ello, presenta una aleación compositiva muy evolucionada, que - entre otros parámetros- justificaría parcialmente su modernidad entre las del tipo Monachil.

\section{III.B. ANDALUCía Oriental}

Esta región andaluza, relacionada con la Cuenca Alta del Guadalquivir, ha proporcionado en los últimos treinta años el conjunto más voluminoso de fíbulas tipo Monachil. Son catorce documentadas y restos previsibles de alguna otra más: es decir, más del $50 \%$ del volumen peninsular. Su ausencia en la región malagueña y, especialmente, almeriense es paradójica, porque aquí, desde las investigaciones de los hermanos Siret, se han documentado multitud de sepulturas del Bronce Final y hubiera sido de esperar un panorama más prolífico de estos artilugios. También es de destacar la inexistencia de otras fíbulas de las denominadas siculas, como pueden ser las de tipo ad occhio $\mathrm{y}$ arco descentrado.

3. Cerro de la Encina (Monachil, Granada). Este importantísimo asentamiento, con secuencia ocupacional desde un Cobre evolucionado con campaniforme hasta época protohistórica, es conocido desde antiguo (Cabré, 1922). Aunque sus mejores resultados y mayor conocimiento se han obtenido a partir de las excavaciones que, de forma intermitente, se realizan desde 1968 por el Departamento de Prehistoria de la Universidad de Granada (Arribas et alii, 1974). De aquí proceden dos fíbulas de codo que guardan una cierta similitud. La primera de ellas $\left(\mathrm{n}^{\circ} 1\right)$, que daría nombre al grupo, está depositada en el Museo Arqueológico de Granada, registrada como procedente del término municipal de Monachil. Originalmente la dio a conocer W. Schüle (1969), a partir de un escueto dibujo. Una mejor documentación la proporciono años más tarde F. Molina (1977), cuyo dibujo a lápiz nos ha servido de base para el que publicamos en este trabajo (Fig. 2: 6). Tiene configuración de triángulo isósceles, con una base de $7,4 \mathrm{~cm}$, brazos de 6,4 y $5,4 \mathrm{~cm}$ y una altura de $4,7 \mathrm{~cm}$. El codo centrado es alto y estrecho, como una prolongación natural y sin estrangular de los brazos curvos del puente. Su fina sección es oval aplanada. Le falta la aguja y media espira en el resorte, mientras los dos brazos del puente están decorados por tres estrechas bandas incisas, rellenas por finos trazos oblicuos. Se realizó en bronce binario con un porcentaje medio/ bajo de Sn $(6,86 \%)$ (Hook et alii, 1987).

Esta fíbula fue relacionada en origen por W. Schüle, y posteriormente por F. Molina, con el ejemplar aparecido en la fase Va de Megiddo y una cronología de los siglos XI-X a.C. (Schüle, 1969, 25). Por su parte, F. Molina, en su tabla tipológica sobre el Bronce Final del Sudeste, la situó grosso modo en un Bronce Final I, que en aquellos momentos fechó entre el 1100-850 a.C. (Molina, 1978, 215 y Tabla tipológica.).

En nuestra opinión, por cronología sensu stricto, esta fíbula puede tener cabida tanto en la datación de 
W. Schüle, como en el amplio estanco que ocupa el Bronce Final I en la tabla de F. Molina. Pero su apoyo en la cronología y tipología de la fíbula de la Fase Va de Megiddo no resulta muy fiable, en la actualidad. Aunque es evidente que, hasta fechas relativamente recientes, este ejemplar oriental constituyó el paralelo más exótico y paradigmático para sustentar las investigaciones difusionistas de la época y de tiempos posteriores. Parte de su problemática cronológica ya fue expuesta recientemente (Carrasco y Pachón, 2006c), comprobándose dataciones inseguras entre los siglos XII y IX a.C. Aunque, no hace mucho, se ha ofertado una fecha absoluta más firme del $2817 \pm 23 \mathrm{BP}$ (Sharon et alii, 2007, 36, Table 7), que daría con mayor seguridad una cronología del s. X a.C. En relación con las semejanzas tipológicas observadas entre este ejemplar oriental y la fíbula de Monachil hemos de indicar que, efectivamente, el perfil en forma de triángulo isósceles y la amplia base de las dos, junto a un codo alto y centrado, les da un cierto parecido; como, en este aspecto, también lo tiene con las antiguas de Kourion, Larnaka, Amathus, etc. Sin embargo, la de Megiddo presenta brazos moldurados y la de Monachil lisos, lo que constituye un matiz claramente diferenciador. Además, consideramos que debe tener, en el grupo que estudiamos, una cronología alta.

La segunda fíbula del Cerro de la Encina $\left(\mathrm{n}^{\circ} 2\right)$ (Fig. 2: 7) procede de trabajos de excavación reglada, realizados en la campaña 2003/2004 por el Departamento de Prehistoria de la Universidad de Granada. Apareció en el corte/56, zona B, sector A, siglada con el número identificativo Mo-56105, en un contexto postdeposicional mezclado, por lo que no es conveniente asociarla a ningún otro tipo de registro. De fina sección ovalada, le falta la aguja y media espira del resorte. Su perfil tiene una longitud máx. de $7,4 \mathrm{~cm}$, y una altura total de $3,2 \mathrm{~cm}$. El codo es centrado, más abierto que en el ejemplar anterior y algo inclinado hacia la derecha, por la configuración de una fuerte inflexión del brazo derecho.

Las diferencias morfométricas entre estas dos fíbulas son mínimas. Tienen similares tamaños de perfil, aunque los brazos de la primera son de mayores dimensiones, al no sufrir distorsión alguna en la configuración del codo, lo que lo hace estar más centrado, frente a la sensación de su inclinación en la segunda, por la inflexión de uno de ellos. Esta última se realizó en un bronce binario con contenido de Sn medio/bajo (6,3\%). La fíbula, por tipología, es algo más antigua que la anterior, con composición metalográfica similar, ausencia de decoración en el puente y algo más aplanada. Puede tener una cronología entre los siglos XII/XI a.C., acorde con horizontes culturales detectados en este enclave arqueológico.

4. Cerro de la Mora (Moraleda de Zafayona, Grana$d a$ ). De amplia bibliografía, este extenso asentamiento de gran secuencia habitacional, fundación argárica y poblamiento -más o menos- continuado hasta época
Alto medieval, tuvo especial énfasis en lo referido al Bronce Final, Fenicio y Protoibérico, habiendo proporcionado su excavación, desde finales de los años setenta hasta principios de los noventa, una gran variedad de elementos broncíneos elaborados en talleres metalúrgicos del propio enclave arqueológico. Entre otros, destacan artilugios relacionados con objetos de vestir, como fíbulas y botones. De las primeras, al margen del ejemplar tipo Huelva, documentado en estratigrafía junto a una espada de lengua de carpa en el sector de la Miel, publicada hace casi treinta años (Carrasco et alii, 1985 y 1987) y muy referenciado en bibliografía, son numerosas las fíbulas estratificadas en el yacimiento, especialmente del tipo Monachil y posteriores de doble resorte, sin olvidar un excelente ejemplar de pivote. El inventario de las primeras, que consideramos, sería: 1. Fragmento del brazo derecho de un puente con restos de codo centrado, resorte de espira y media y gran parte de la aguja, fusiforme. 2. Restos de los brazos del puente y codo centrado, sin resorte, mortaja, ni aguja, fusiforme. 3. Parte de un puente con codo centrado, falta parte de los brazos, resorte, mortaja y aguja, filiforme. 4. Fragmento de un brazo derecho con restos del resorte, fusiforme. 5. Fragmento de un brazo derecho y restos del resorte, filiforme. 6. Fragmento de brazo derecho con restos del codo centrado, resorte de espira y media y restos de aguja, filiforme. 7. Fragmento de un brazo derecho, con restos de codo centrado, resorte de espira y media con aguja, fusiforme. 8. Dos fragmentos que componen una fíbula partida por el puente de codo centrado, resorte de espira y media, mortaja, levemente fusiforme. 9. Fragmento del brazo de una posible fíbula de codo de gran tamaño. Todas tienen muy mal estado de conservación, por lo que no han sido objeto de ningún análisis metalográfico, aunque es una posibilidad que seguimos valorando. En lo posible, serán objeto de un trabajo próximo de investigación, junto con algunos de los registros cerámicos y metálicos que se le asociaban. A priori, la cronología de este conjunto de fíbulas, posiblemente deba situarse entre los siglos XIII/XII y la primera mitad del IX a.C.

5. Las Agujetas (Pinos Puente, Granada) (Fig. 2: 8). No es la primera vez que nos ocupamos de este sitio arqueológico, por lo que su bibliografía puede seguirse en los estudios previos del yacimiento (Pachón et alii, 1979; Pachón y Carrasco, 2009 y 2010; Carrasco et alii, 2012). El Cerro de las Agujetas conforma un pequeño enclave con funcionalidad complementaria respecto del Cerro de Los Infantes, probablemente frecuentado a fines de la Edad del Bronce, que prolongaría su uso hasta tiempos romanos. Aunque es probable que albergara algún reducto funcional de carácter económico e incluso militar, una parte importante de los hallazgos también aluden a la presencia de espacios con utilidad funeraria, de los que podría proceder una fíbula tipo Monachil, junto con otras dos del grupo Huelva (Carrasco et alii, 2012). El caso que aquí concurre corresponde al brazo izquierdo de un puente 
de configuración fusiforme, con máxima sección en el centro que se afina hacia el codo y pie. Su parte inferior está decorada con diez finas líneas paralelas incisas, que pudieron existir en menor número por la parte superior o exterior. Conserva el inicio del pie o mortaja, insinuándose también parte del codo. Su longitud máxima es de $2,8 \mathrm{~cm}$, sección oblonga de $8 \times 6$ $\mathrm{mm}$. Su longitud reconstruida rondaría los $5 \mathrm{~cm}$, con el codo centrado en el puente. Se fundió en un bronce binario con un porcentaje medio de $\mathrm{Sn}(9,0 \%)$. Un dato novedoso, de interés en esta fíbula, es que presenta una perforación y restos de otra realizada con un taladro continuo (tecnología tardía en el Bronce Final), de forma paralela y superpuesta en el codo, que debieron tener correspondencia en el brazo perdido del puente. Estas perforaciones se realizaron, o bien para unir los brazos tras su rotura en el vértice del codo, o fueron realizadas ex profeso para enrollar hilos consistentes con fines decorativos, como se ha comprobado en algunas fíbulas chipriotas antiguas (Buchholz, 1986). En último caso, y menos probable, para fortalecer o prevenir posibles fracturas por el lugar más débil de la fíbula. A priori, la cronología de esta fíbula pudiera situarse, con ciertos argumentos, a lo largo del siglo IX a.C. Paralela en el tiempo, en territorios andaluces, con las últimas producciones de las de tipo Huelva. Por morfometría es idéntica al ejemplar liso de la Ría de Huelva, estudiado por Almagro Basch.

6. Canto Tortoso (Gorafe, Granada) (Fig. 2: 9). Del entorno de este extenso asentamiento arqueológico sin excavar, procede un fragmento de fíbula del tipo que estudiamos. Considerado por sus registros cerámicos de superficie de dilatada cronología ibérica, es evidente que debe ampliarse su secuencia en profundidad. Es conocido desde mediados de los años noventa (González et alii, 1995) y se localiza en una amplia meseta, en la confluencia de los ríos Fardes y Guadiana Menor; área geográfica de gran tradición arqueológica, especialmente durante la Prehistoria reciente. La problemática de su poblamiento ha sido sintéticamente expuesta en un trabajo moderno (Carrasco y Pachón, 2002), pero el fragmento de fíbula relacionada con el yacimiento lo dimos a conocer de forma esquemática en los años noventa, indicando su procedencia de un lugar indeterminado de la amplia geografía de Guadix (Carrasco et alii, 1999). Hoy día, puede concretarse su hallazgo en Canto Tortoso, perteneciente al término de Gorafe, en la extensa región de la Hoya de Guadix. Está compuesto por el brazo derecho del puente y parte del codo, resorte con espira y media y fragmento de la aguja, ligeramente curva. Por su configuración de perfil alto, en forma de triángulo isósceles, debió tener el codo centrado. Su sección es ligeramente curva, por su parte inferior y apuntada o triangular, por la superior. Es de configuración levemente fusiforme, estrechándose por sus extremos, para conformar resorte y codo. Su base aproximada sería de unos $7 \mathrm{~cm}$, altura $4,5 \mathrm{~cm}$, sección máxima/mínima 6 y $3,5 \mathrm{~mm}$.
Se fundió en un bronce binario, con porcentaje medio/ bajo de Sn $(6,4 \%)$. No tenemos excesivos datos para adjudicarle una cronología firme, aunque grosso modo consideraríamos una fecha antigua entre las del grupo.

7. Las Muelas (Alamedilla, Granada) (Fig. 2: 10). Gran asentamiento sin excavar, localizado en la parte nororiental del término municipal de Alamedilla, comarca de los Montes Orientales granadinos, en los límites de Huelma y Cabra del Santo Cristo, municipios del Subbético jienense. Se sitúa sobre una serie de altozanos calizos (muelas), algunos por encima de los 900 m s.n.m., dominando tierras de secano y regadío, pertenecientes a la cuenca del Río Guahortuna; sus aguas, junto con las del Guadiana Menor, constituyen el aporte hídrico de las cuencas fluviales más importantes de esta región. Es un yacimiento conocido superficialmente desde antiguo, con registros arqueológicos adscribibles a toda la secuencia del Bronce y tiempos posteriores. De este lugar, y sin excesivos datos, procede una fíbula completa inédita del tipo Monachil, de sumo interés por la tipología y metales en que se fundió. Su perfil es de triángulo isósceles con amplia base $(6,9 \mathrm{~cm})$, baja altura $(2,6 \mathrm{~cm})$, brazos filiformes, sección ligeramente oblonga $(3,5 \times 2 \mathrm{~mm})$ y fina aguja (2 $\mathrm{mm})$. El codo, bien marcado, se inclina sobre el brazo izquierdo por su mayor inflexión respecto del derecho. La mortaja mide $1,9 \mathrm{~cm}$ y el resorte, con espira y media, es pequeño e irregular. Posiblemente fue obtenida a partir de una varilla de sección cuadrangular desgajada de una placa fundida, con una elaboración final de limado y mortaja martilleada. Como hemos indicado, el interés de esta fíbula, al margen de sus características morfométricas arcaicas, reside en el metal o metales en que fue fundida, bien con arsénico (As $=1,5 \%)$ o en cobre puro $(\mathrm{Cu}=99,2 \%)$, análisis que posteriormente comentaremos. En síntesis, consideramos que se trata de una de las fíbulas más antiguas de todo el Occidente mediterráneo, si no lo es ya de entre los conocidos registros fibulares antiguos de la Península Ibérica.

8. Cerro Alcalá (Mancha Real/Torres, Jaén) (Fig. 2: 11). De este extenso enclave arqueológico, que por su extensión se localiza en la confluencia de varios términos municipales, como Mancha Real, Torres y Jimena, hace ya casi treinta y cinco años que dimos a conocer una extraordinaria fíbula de codo procedente de una incineración en urna, posiblemente del entonces considerado Bronce Final Pleno (Carrasco et alii, 1980). En aquellos momentos la estudiamos y asemejamos tipológicamente con otros ejemplares peninsulares y orientales, muy propios de la época en cuestión. Así como con algunas decoraciones conocidas en otros artilugios, especialmente brazaletes, entre ellos los extremeños del yacimiento de Berzocana. Cuestión que tuvo gran trascendencia en trabajos posteriores y entre investigadores que, a falta de mejores argumentos que hoy sí existen, la han actualizado para justificar y encubrir ciertas carencias de temática fibular. 
El ejemplar es de los que cabría calificar de prestigio, lo mismo que pudo ocurrir con la de Casa Nueva, también de Pinos Puente, aunque ya entre las del tipo Huelva; la de las Lunas de Yuncler (Toledo), entre las de arco descentrado; incluso la de Mola dAgres (Alicante) dentro del tipo ad occhio, o el ejemplar inédito de pivote del Cerro de la Mora, de nuevo en Moraleda de Zafayona, Granada.

La de Cerro Alcalá sería una fíbula extraordinaria por fundición, dimensiones y decoración, propia de un status elevado. Tiene un perfil de triángulo isósceles con amplia base $(9,5 \mathrm{~cm})$ y una altura de $3,8 \mathrm{~cm}$, la sección lenticular está definida en los brazos (sección máxima $8 \mathrm{~mm}$; sección mínima $3 \mathrm{~mm}$ ), mientras el codo es estrecho, alto y centrado. Presenta un amplio pie o mortaja (dimensión máxima $2 \mathrm{~cm}$ ) y un resorte que, en origen, debió tener tres espiras. Se fundió en un bronce binario, con porcentaje medio/bajo de $\mathrm{Sn}$ $(6,28 \%)$. Los brazos están decorados en su parte superior, ambos presentan tres fajas perpendiculares a sus ejes, distribuidos desde la parte media del codo, por la parte central de los brazos, hasta las proximidades del resorte y la mortaja. Las fajas se componen de finas incisiones paralelas que, en número de 5 ó 6 , enmarcan triángulos apuntados rellenos de finos reticulados $\mathrm{y}$, entre ellos, rombos lisos exentos. Su cronología $a$ priori puede ser discutida, pues su morfometría, tipo de aleación en que se fundió y contexto cerámico asociado, no son muy acordes. En nuestra opinión, podría situarse entre la segunda mitad del s. X y la primera del IX a.C.

\section{III.C. LEVANTE}

En el área levantina solo se han documentado dos fíbulas incompletas de las que estudiamos, en la Peña Negra de Crevillente. Tienen contextualización estratigráfica, aunque los registros arqueológicos asociados están en fase de análisis, por lo que cronológicamente son de difícil precisión. En los estudios de fíbulas realizados en la región, solamente habría que destacar la presencia de otros dos ejemplares de los denominados sículos: la de codo descentrado depositada en el SIP de Valencia, de origen desconocido y la tardía ad occhio de Mola d'Agres.

9. La Peña Negra (Crevillente, Alicante). En tan importante enclave arqueológico, de amplia tradición bibliografía, se localizaron restos de dos fíbulas de codo en el Corte G, adyacente al Corte E (González Prats, 1992), abierto en la campaña de 1987 y que, como todo su registro, permanecían inéditas En él se excavó un amplio y estratificado depósito de residuos del Bronce Final cubierto por tierras de labor, proporcionando una secuencia compuesta por nueve estratos de ocupación y derrubios. Las fíbulas aparecieron en la parte inferior del estrato 7 denominado IIb4, asociadas grosso modo a un amplio conjunto de materiales de la más diversa etiología, entre los que destacan fragmentos de brazaletes de marfil que ya se conocían en otros registros del poblado, así como en el ajuar de algunas sepulturas de cremación de Les Moreres (González Prats, 2002). Las dos fíbulas en cuestión corresponden: en primer lugar ( $\mathrm{n}^{\circ} 1=$ PN.13920), al brazo izquierdo de un puente $(4,2 \mathrm{~cm})$ de sección circular $(0,6$ $\mathrm{cm}$ ), mortaja completa y restos del codo (Fig. 3: 1). La segunda $\left(\mathrm{n}^{\circ} .2=\mathrm{PN}-13919\right)$ está compuesta por restos del brazo izquierdo del puente, en el que se insinúa el inicio de la mortaja y el brazo derecho con codo central incluido, más los inicios del resorte. El puente fusiforme es de sección oblonga $(0,8 \times 0,4 \mathrm{~cm})$ y sus dimensiones reconstruidas serían, aproximadamente, de unos $7 \mathrm{~cm}$ de longitud y $3,5 \mathrm{~cm}$ de altura (Fig. 3: 2). $\mathrm{Su}$ cronología aproximada se situaría entre los siglos $X$ y IX a.C., con una mayor antigüedad para la primera $\left(\mathrm{n}^{\mathrm{o}} 1\right)$ que para la segunda $\left(\mathrm{n}^{\mathrm{o}} 2\right)$.

\section{III.D. MeSETA}

De este extenso territorio peninsular, rico en producciones broncíneas de todo tipo y de una sugerente y variada muestra de las consideradas fíbulas antiguas de codo (Huelva, ad occhio, violín, etc.), extrañamente solo se ha documentado un ejemplar del tipo $\mathrm{Mo}$ nachil. Por desgracia, a partir de una información de relativa validez, diríamos que anecdótica.

10. Mansilla de las Mulas (Lancia, León) (Fig. 3: 3). Existen en bibliografía muchas referencias de esta fíbula, pero en realidad todas provienen de los escasos datos que, en su momento, proporcionó W. Schüle (1969). Que, a su vez, los obtuvo junto a un dibujo esquemático de D. Eladio Isla. En su investigación, Schüle incluye este ejemplar, junto al de Monachil y la del tipo Huelva de Burgos, en su Tipo «Ia», el más antiguo entre las fíbulas peninsulares por él clasificadas.

Es una fíbula de perfil alto, con forma de triángulo isósceles y base estrecha. Le falta parte de uno de los brazos del puente, el resorte y la aguja. El codo aparece centrado y la sección de brazos es tan gruesa que, en opinión de Almagro Basch, serían "amorcillados» y sin decoración alguna. Su altura aprox. sería de 5,2 $\mathrm{cm}$; anchura máx. 4,2 cm; sección máx. $0,5 \mathrm{~cm}$. La reconstrucción que presentamos se debe al propio $\mathrm{W}$. Schüle.

J. Fernández Manzano, al estudiarla en base al dibujo de Schüle, resaltaba que la fíbula, por no tener ningún tipo de decoración, podía situarse entre las más antiguas de la Península (Fernández, 1986). Aunque, a continuación, apuntaba otra alternativa, al compararla con las lisas aparecidas en el depósito francés de Vènat, consideradas del Hierro Antiguo (al menos el brazo con pie). Por lo que concluía que esta fíbula, en un proceso de simplificación, podría considerarse derivación tardía de los ejemplares «con gallones». Una hipótesis aceptada entre otros por C. Blasco (1987), 
que la comparó con otra fíbula del castro de El Berrueco que desconocemos. En realidad, de este yacimiento proceden tres fíbulas antiguas (arco de violín, ad occhio y Huelva), que entrarían en el taxón codo, sin similitud con la de Mansilla. Esta fíbula no nos parece derivada de ninguna otra de gallones (tipo Huelva) y, aún menos, surgida en un proceso de simplificación. En todo caso, constituiría sin más, una derivación o producción retardataria local, dentro de las del tipo Monachil.

\section{III.E. EXTREMADURA}

En los últimos años, el ámbito extremeño, junto a la Alta Andalucía, ha proporcionado en la Península

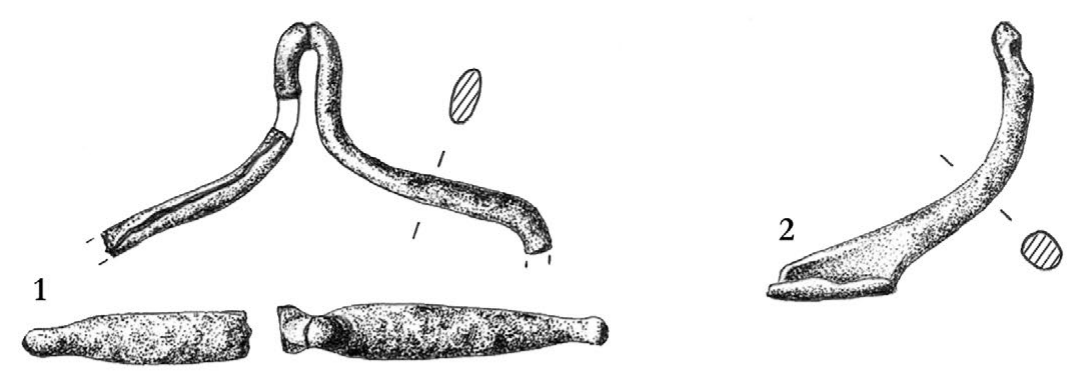

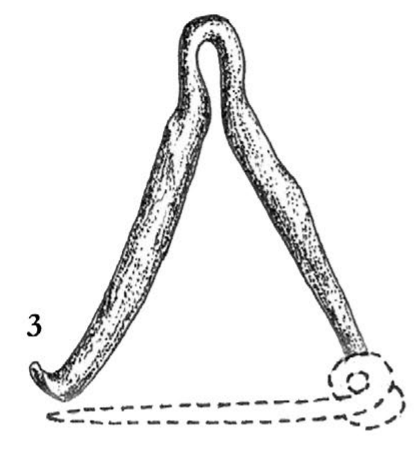
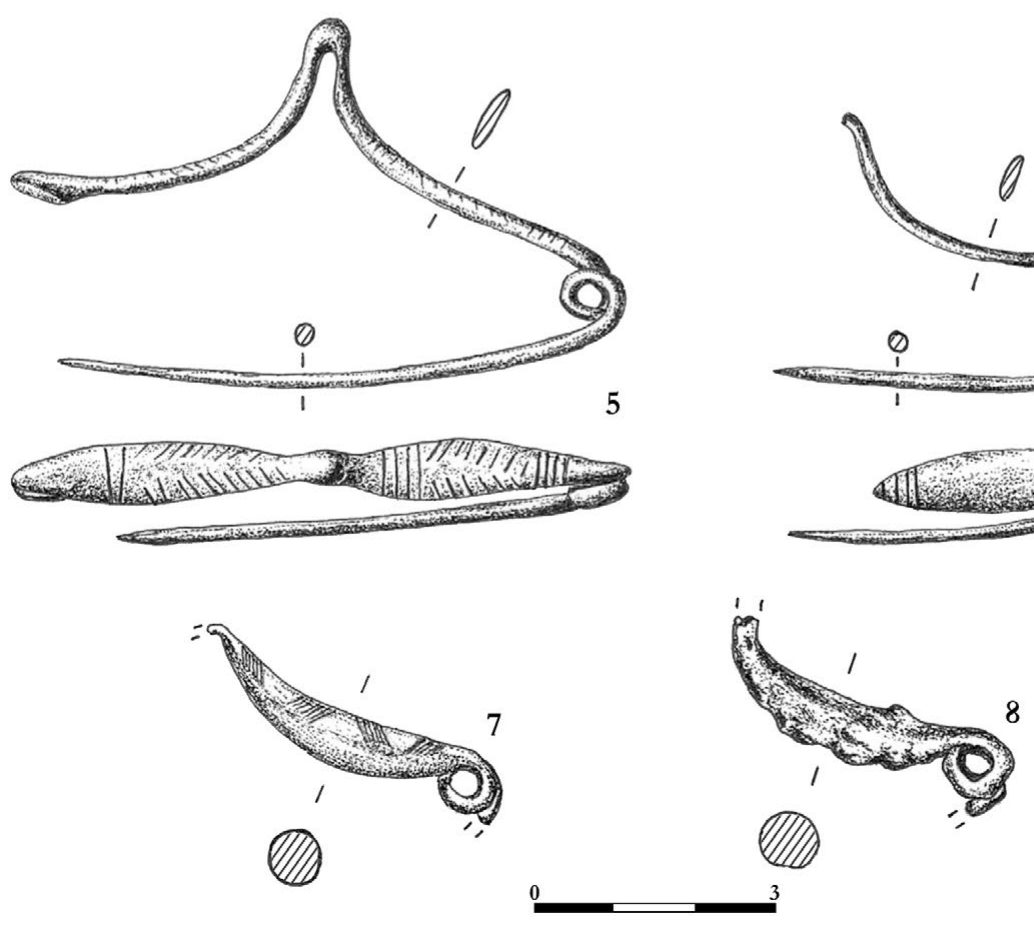

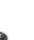

(1)
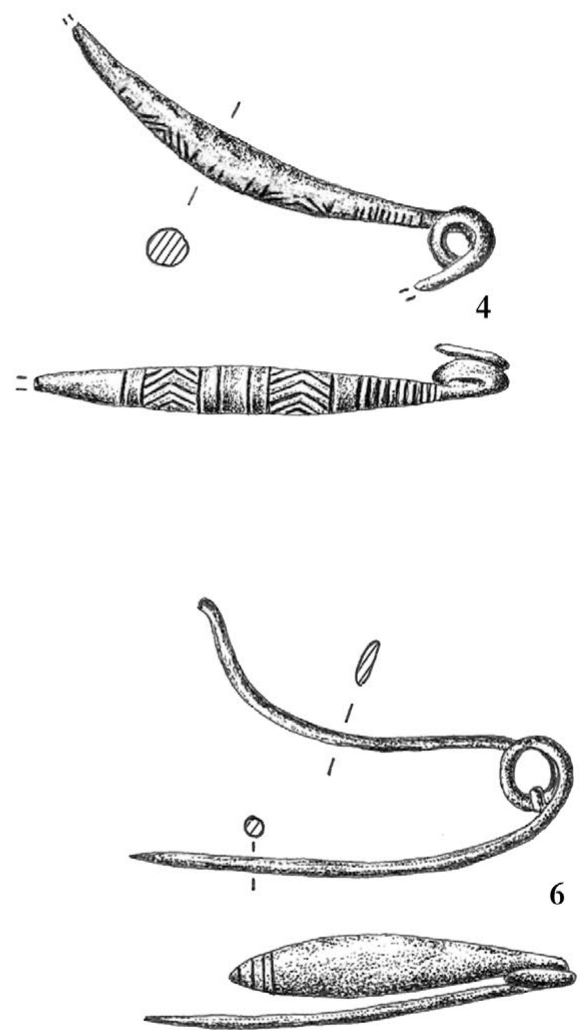

6 (1)

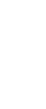


Ibérica el mayor número de fíbulas del tipo que estudiamos. Cuestión lógica, por el dinamismo de las poblaciones del Bronce Final en estos ámbitos geográficos, y por el amplio registro habitacional constatado. Número de fíbulas que tendrá que incrementarse cuando se detecten y excaven las necrópolis que se les asocian, como debe ocurrir en otras áreas peninsulares. Tres son los extensos asentamientos extremeños que han proporcionado, producto de recogidas superficiales no contextualizadas, cinco fíbulas del tipo Monachil.

11. Talavera la Vieja (Cáceres). Núcleo poblacional situado en la orilla izquierda del Tajo, conocido desde antiguo por sus conjuntos monumentales romanos arruinados. Fue cubierto en los años sesenta, junto a numerosos enclaves arqueológicos de su entorno, por el embalse de Valdecañas. En los años en que la sequía afecta en la zona, desciende el nivel de las aguas del pantano, aflorando vestigios arquitectónicos y restos habitacionales, junto con registros arqueológicos de diversa entidad. De uno de estos lugares, fuera de la villa de Talavera, se documentaron y estudiaron restos de tres fíbulas de codo, así como un sugerente conjunto cerámico a mano y a torno descontextualizado ( $\mathrm{Ji}$ ménez y González, 1999). Así aparecieron dos fíbulas del tipo Huelva y otra del tipo Monachil. De las dos primeras, conocidas por la amabilidad de A. González y depositadas en la Colección Durán en Navalmoral de la Mata, realizamos análisis metalográficos y fueron de nuevo documentadas e incluidas en nuestras tablas tipológicas del tipo (Carrasco y Pachón, 2006b).

La tercera (Fig. 3: 4), del tipo Monachil y depositada en el Museo de Cáceres, conserva el brazo derecho del puente con resorte de espira y media y restos de la aguja. Falta la inflexión del codo, que debía estar centrado, mientras la sección del brazo es circular. Entraría, por su configuración, entre las «amorcilladas» de Almagro. Según sus descubridores (Jiménez y González, 1999), esta fíbula fue fundida a la cera perdida, en base al tipo de decoración no incisa en frío que ocuparía toda su superficie. El ornato lo componen tres fajas lisas delimitadas por finos trazos que, a su vez, encuadran otras rellenas con motivos angulares paralelos, junto a una gran faja con líneas paralelas, que delimitan el inicio del resorte. El brazo conservado tiene una long. máx. de 5,6 cm y sección máx. de 0,6 cm.

Aunque los autores especulan sobre la disimetría del codo de esta fíbula, para defender la opción de su origen siciliano, pensamos que aquel debió estar centrado, conformando una fíbula alta en forma de triángulo isósceles, sin paralelos entre los modelos italianos. Fue fechada por sus investigadores entre los siglos XI y VIII a.C. En nuestra opinión, precisaríamos su cronología entre la segunda mitad del s. X y la primera del IX a.C.

12. La Muralla (Valdehúncar, Cáceres). De este importante asentamiento arqueológico localizado en la comarca de Campo Arañuelo, en el tramo medio del
Tajo y dentro de la Alta Extremadura, procede un rico registro arqueológico de diferente origen, obtenido en recogidas superficiales (Barroso y González, 2007). Sus investigadores señalan en este conjunto la presencia de dos fíbulas que consideramos del tipo Monachil. La primera de ellas ( $\mathrm{n}^{\circ}$ 1) (Fig. 3: 5) se conserva íntegra, con el codo centrado, brazos de planta fusiforme y sección oblonga plana. De pie corto, aguja de sección circular (sección máx. $0,3 \mathrm{~cm}$ ) y resorte de una espira, presenta una decoración de motivos incisos en la parte superior de los brazos, compuesta en cada uno de ellos por dos fajas perpendiculares de incisiones paralelas a sus ejes máximos, próximas al resorte, codo y pie, que en su amplio sector central enmarcan trazos oblicuos paralelos, con motivo de espigas. Su perfil tiene forma de triángulo isósceles, de amplia base $(7,9 \mathrm{~cm})$ y altura relativamente baja (aprox. 3,2 cm). La sección máx. es de 0,7 cm. La segunda fíbula $\left(\mathrm{n}^{\mathrm{o}} 2\right)$ (Fig. 3: 6), incompleta, conserva sólo el brazo derecho del puente y restos del codo, resorte con espira y media, arete de adorno y aguja. Es de sección fusiforme, presentando, próxima al codo, una decoración de faja con incisiones paralelas. La dimensión del brazo conservado $(5 \mathrm{~cm})$ es similar al de la primera fíbula de codo centrado: $\sin$ embargo, en este caso, quizás porque está distorsionada y la aguja posiblemente incompleta, se especula en este ejemplar con una asimetría difícil de entender, cuando falta el brazo izquierdo. Aunque resulta suficiente para seguir manteniendo el consabido carácter sículo de estas fíbulas en la bibliografía tradicional, lo que no es necesario comentar. Para nosotros, serían dos fíbulas muy similares, de codo centrado y cronología que -en principio-sería algo más antigua que la fecha ofertada para la procedente de Talavera la Vieja; es decir, entre la segunda mitad del siglo XI y primera del X a.C.

\section{Los Concejiles (Lobón, Badajoz) (Fig. 3: 7-8).} De este gran asentamiento proceden dos fragmentos de fíbulas de codo, recogidas en superficie junto con diversos bronces y una extensa muestra cerámica de amplio espectro cronológico, poco especificado. Aunque los restos fibulares eran conocidos con anterioridad (Jiménez Ávila et alii, 2002), es una investigación más reciente donde se realiza, según sus autores, el estudio más detallado (Vilaça et alii, 2012). Pero es un trabajo con el que no coincidimos, entre otras cuestiones, por el tratamiento que se da a las fíbulas. En principio, sus investigadores las catalogan como «tipo de sección circular-ovoide» (Vilaça et alii, 2012, 48), lo que, dentro de las fíbulas de codo en general, no indica nada, ni es parámetro para definir un tipo concreto de fíbula. Se describen como de puente disimétrico ( $i ?)$, cuando sólo se conserva un brazo en cada una de ellas. También se indica un «resorte, el clásico de una sola vuelta» (Vilaça et alii, 2012, 149), que no resulta ser ni clásico, ni de una sola vuelta. Se comparan con las dos procedentes de Mondim da Beira, cuya problemática veremos en el apartado de Portugal. Entre las extremeñas, los autores las asimilan con el ejemplar cacereño 
de La Muralla de Alcántara, que hace años documentamos a partir del dibujo y fotografía proporcionados por J. Esteban, de puente con decoración única y codo totalmente descentrado, muy diferente a las de Los Concejiles. También las paralelizan con las procedentes de los yacimientos cacereños de Talavera la Vieja y Muralla de Valdehúncar y del portugués de Nossa Senhora da Cola. Recordemos que, del primero de estos yacimientos, dos fibulas serían del tipo Huelva, tipológicamente ajenas a las de Los Concejiles, y una tercera de sección circular, que consideramos de codo centrado, sí puede estar relacionada con su ejemplar decorado. Del segundo yacimiento, los dos ejemplares estudiados son de perfil diferente y no «del tipo de sección circular ovoide», al que aluden los investigadores de Concejiles. En resumen, los investigadores de Los Concejiles muestran un conocimiento relativo del tema fibular, que completan con el añadido de un mapa (Vilaça et alii, 149) inespecífico, falto de contenido y controvertido, en el que se señalan sólo «la dispersión de las fibulas de codo tipo Huelva y variantes, no incluyendo las de tipo 'ad occhio', lo que excluye los ejemplares de Baleizao y N.S. da Cola en la zona de estudio» (Vilaça et alii, 150), junto al paradigma de una fíbula de Mondim da Beira, según los autores de las del tipo Huelva y variantes (s.c.). Finalmente, la cronología que ofrecen para estas fibulas, como para el resto del registro arqueológico, entre los siglos XI-IX a.C., no es del todo preciso, pero acorde con las peculiaridades de su estudio.

Estimamos que las fíbulas de Concejiles, por las dimensiones de los brazos conservados $(3,5$ y $4 \mathrm{~cm}$ aprox.) y la configuración de su posible puente, entrarían en los parámetros de las de codo centrado. Sus análisis metalográficos indican una aleación binaria con contenidos de Sn del 13,6\% $\left(\mathrm{n}^{\mathrm{o}} 1\right)$ y $10,8 \%\left(\mathrm{n}^{\mathrm{o}} 2\right)$, propios de una metalurgia del Bronce Final relativamente avanzada, aunque no muy tardía; pero, sin lugar a dudas, más antiguas que las portuguesas de Mondim da Beira, con las que no tienen excesivas semejanzas morfométricas, ni de composición metalográfica. Al margen de otras cuestiones tipológicas, ocuparían un espacio cronológico entre el siglo $\mathrm{X}$ y la primera mitad del IX a.C.

En resumen, y sin mayores detalles, de las nueve fíbulas de codo registradas actualmente en Extremadura, al margen de las múltiples representadas en las estelas, casi todas de puente asimétrico, dos serían realmente del tipo Huelva (Talavera la Vieja), cinco del tipo Monachil (Talavera la Vieja, Muralla de Valdehúncar y Concejiles) y otras dos de puente asimétrico (Muralla de Alcántara y Pajares).

\section{III.F. PoRTUGAL}

Son escasas las fíbulas de codo antiguas que, actualmente, se cotejan en la geografía portuguesa. Más aún, consideramos que, dentro de los tipos generales que hemos establecido para ellas, ni sus ejemplares ad occhio (Casal do Meio, S. Româo, Santa Luzia), ni las tipo Huelva (Abrigo Grande das Bocas), ni menos aún las sículas (Mondim da Beira, Monte Airoso, N.S. da Cola), tienen cronologías arcaicas y alguna ni entraría en el taxón de codo antigua, como puede suceder con uno de los ejemplares de Nossa Senhora da Cola.

14. Mondim da Beira. En 1986, S. da Ponte daba a conocer un fragmento de puente de fíbula (Fig. 4: 2) depositada en el Museo Nacional de Arqueología y Etnología de Portugal (Da Ponte, 1986). Inventariada con el $\mathrm{n}^{\mathrm{o}} 14299$, sin contexto arqueológico alguno, fue incluida, siguiendo nomenclaturas francesas, en la primera categoría del amplio grupo de fíbulas de arco multicurvilineo. En su interpretación, siguiendo a Sundwall, S. da Ponte consideraba esta modalidad de origen italiano y la situaba entre los siglos IX y VII a.C., siendo frecuente, según esta investigadora, en los finales del siglo VIII e inicios del VII a.C. En un posterior trabajo (Da Ponte, 1989), incluía esta fíbula en el complejo y fragmentario mosaico que constituye la última fase del Bronce Atlántico, fechándola en el curso de los siglos IX-VIII, que en territorio portugués, según esta autora y siguiendo modelos de Coffyn y Blasco, no sería anterior a la primera mitad del siglo IX a.C.

Más recientemente, esta fíbula fue «de nuevo» publicada (Fig. 4: 3) por J. R. Carreira (1994), junto con otro ejemplar, al parecer proveniente del mismo sitio (Fig. 4: 4). Indica este autor que tales fíbulas fueron dadas a conocer de forma aislada, sin reconstruir, por parte de Leite de Vasconcelos en 1933 y, desde entonces, habían pasado inadvertidas para la bibliografía arqueológica subsiguiente. Ignorando así los trabajos de S. da Ponte, de modo inconsciente o, quizás, debido al dibujo esquemático y muy diferenciado que esta autora había presentado de la primera fíbula.

Esa primera fíbula $\left(\mathrm{n}^{\circ} 1\right)$ (Fig. 4: 5) que, gráficamente, reconstruimos a partir de los dibujos de S. da Ponte (Fig. 4: 2) y J. R. Carreira (Fig.4: 3), corresponde al brazo derecho del puente de una fíbula de codo de sección oblonga, conservándose el inicio del codo y una espira y media del resorte. La decoración está compuesta por una ancha faja central, que ocupa gran parte del brazo, con una serie de incisiones paralelas al mismo, delimitadas por dos fajas más cortas de incisiones perpendiculares paralelas, pero enmarcadas -a su vez- por dos incisiones más fuertes en el mismo sentido. La decoración, en el dibujo de S. da Ponte, muestra que también invade la parte inferior del puente, como sucede en otras del mismo tipo y en alguna otra del tipo Huelva, como la de San Román de Hornija. En su reconstrucción, J. R. Carreira, según nuestros criterios, la orienta mal y los brazos resultantes quedan muy asimétricos, con el codo en un lateral, descansando sobre el brazo que sustenta la mortaja. Por contra, la orientación normal de esta fíbula ofrecería brazos posiblemente más simétricos y codo centrado. Sus dimensiones aproximadas son: $4,5 \mathrm{~cm}$ de longitud, en la parte conservada, y $0,8 \mathrm{~cm}$ de sección. 
La segunda fíbula ( $n^{\circ}$ 2) (Fig. 4: 6) es de mayores dimensiones y más completa, ya que conserva entero el brazo derecho, con una espira y media en el resorte, el codo fragmentado y parte del brazo izquierdo, habiendo perdido la mortaja. El brazo derecho tiene una gruesa sección circular, siendo la del izquierdo ligeramente elíptica. Presenta una profusa decoración en los brazos, a base de finas incisiones paralelas que se desenvuelven a lo largo de ellos, hasta formar una ancha faja central delimitada en sus extremos, cerca del codo y del resorte, por dos o tres incisiones más fuertes, paralelas y perpendiculares a los mismos. Esta fíbula también la consideramos mal reconstruida (Fig.4: 4) y, aunque es evidente una cierta asimetría original entre los brazos, su excesiva inclinación hacia el brazo de la mortaja, y la pérdida de ésta, ha dado lugar a un modelo de puente descentrado que Carreira paralelizó, en origen, con tipos sicilianos y con el ejemplar conservado en el Museo de Valencia de procedencia desconocida. Sus dimensiones son: $68 \mathrm{~mm}$ de longitud; sección del brazo derecho: $8 \mathrm{~mm}$; sección máx. del brazo izquierdo: $7 \mathrm{~mm}$.

J. R. Carreira, basándose en la alta composición metalográfica en estaño de estas fíbulas, consideró que eran producciones indígenas de la metalurgia del Bronce del Noroeste peninsular y de las Beiras portuguesas. En realidad, estas dos fíbulas son producciones locales retardatarias, como así lo expusimos en alguna ocasión (Carrasco et alii, 1999; Carrasco y Pachón, 2006b). Su alto contenido de estaño, a veces por encima del $40 \%$, apunta en principio hacia lo sugerido por Carreira sobre su indigenismo y elaboración tardía, salvando sus impuestos paralelismos bibliográficos extrapeninsulares. En su momento, señalamos algunas relaciones tipológicas entre los diseños incisos decorativos que presentan estas fíbulas y las estructuras en fajas resaltadas de las del tipo Huelva, pero nunca las consideramos específicamente de este grupo.

15. Monte Airoso (Granja, Penedono). De este castro portugués procede un fragmento de brazo de fíbula recogida en superficie (Fig. 4: 7). Citada en bibliografía como procedente de Monte Calvo, Penedono (Cardoso, 2002, 354), se referenció y comentó posteriormente como de Monte Airoso por R. Vilaça (2008), siendo finalmente reinterpretada por nosotros (Carrasco et alii, 2012). Los investigadores lusos la reconstruyeron a partir del brazo izquierdo, con restos de mortaja y codo $(3,3 \mathrm{~cm})$, dándole una verticalidad impropia; luego, le añadieron un supuesto y extenso brazo derecho, a fin de que el codo ofreciese un marcado aspecto asimétrico y, así, encajarla propiamente entre las de arco descentrado de tipo sículo. En nuestra opinión, por la dimensión y configuración del brazo conservado, el ejemplar tendría el codo centrado, como se ha señalado en otro lugar (Carrasco et alii, 2012). De configuración fusiforme y amplia sección circular oblonga, presenta decoración en su parte central, con motivos de fajas rellenas de motivos reticulados incisos y otros inclinados paralelos alternos. Su cronología podría estar a partir de la segunda mitad del s. X a.C.

16. Nossa Senhora da Cola (Ourique, Beja). (Fig. 4: $1)$. De este castro portugués, hace años que S. da Ponte publicó una fíbula sin contexto alguno (Ponte, 1986b), descrita como de arco multicurvilineo y pie largo, que integró en su tipo «1c» (Ponte, 2006). Según esta investigadora, con una cronología de finales del Bronce Final/Primera Edad del Hierro, entre el siglo VIII-VII a.C. No conocemos directamente esta fíbula, pero consideramos muy posible que no entre en la categoría de las de codo y, menos aún, que pertenezca al tipo Monachil que estudiamos. Sin embargo, de las excavaciones realizadas por A. Viana (1961), en los estratos pre-romanos de la alcazaba de este Castro, procede un fragmento del brazo izquierdo de una fíbula de codo, de la que solo se conserva parte del brazo izquierdo del puente. Presenta decoración de finas incisiones paralelas, enmarcadas por otras transversales. Muy similar al ejemplar del Coronil y en línea con la lisa de la Ría y del Cerro de las Agujetas. Asimismo, tiene semejanzas con las de Mondim da Beira. Nuestra reconstrucción (Fig. 4: 8) es de codo centrado. Su cronología debería ser tardía, posiblemente del s. IX a.C.

\section{METALURGIA, TIPOLOGÍA Y CRONO- LOGÍA}

Se han computado restos de veintinueve fíbulas, de las que veintiséis son reales y tres solo constituyen una posibilidad de difícil filiación, por lo inespecífico de los fragmentos conservados. Existen veinte análisis espectrográficos de catorce de las fíbulas estudiadas, lo que representa un porcentaje relativamente escaso. En cuanto al aspecto concreto de los análisis metálicos, es evidente que - al margen de la ya comentada escasez de la muestra analizada- partimos inicialmente con un problema importante: el hecho de que los diferentes análisis contabilizados proceden de laboratorios que, seguramente, han empleado programas analíticos y técnicas diferentes para su obtención; pero en los que, por ejemplo, no han sido cuantificados los elementos constitutivos, por lo que establecer similitudes, o diferencias entre ellos, es poco significativo en estos instantes. Pese a todo, el hecho de que en su mayor parte procedan de centros analíticos solventes, da ciertas garantías, al obtener análisis que contrastan métodos especializados y modernos, como Espectroscopia de Absorción Atómica (AAS), Microsonda de Electrones (EMPA), Espectrometría de Dispersión de Longitud de Ondas de Rayos X, Difracción de Rayos $X$ y Espectrometría de Plasma Acoplado por Inducción (ICP). Ciertos análisis fueron realizados por el Museo Británico, otros por el Centro de Instrumentación de la Universidad de Granada, Consejo de Investigaciones Científicas de Madrid, dentro del Proyecto Arqueometalúrgico de la Península Ibérica, etc. De otros análisis, 

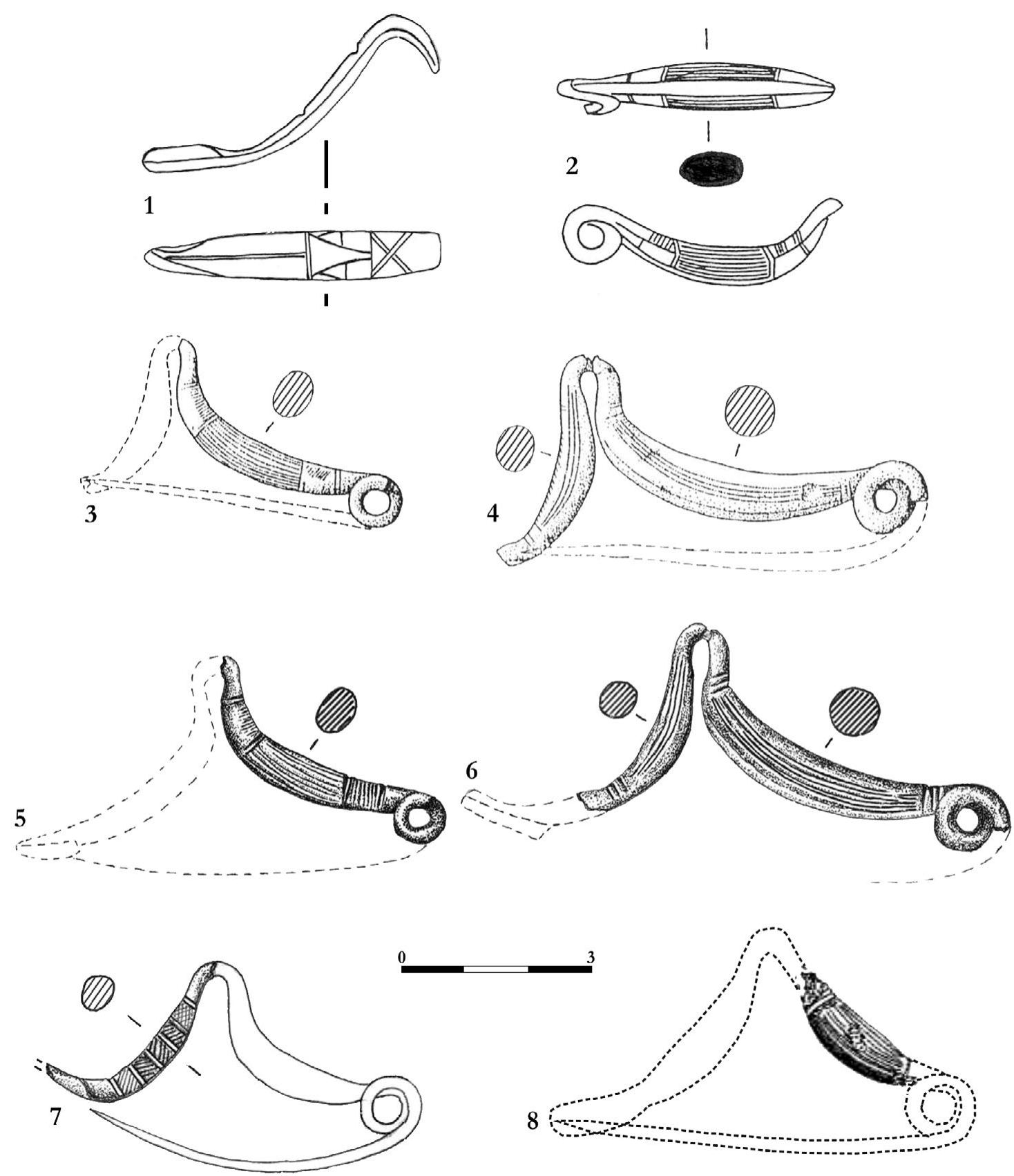

Figura 4: Fíbulas 'sículas' de tipo Monachil. Portugal: 1 y 8. Nossa Senhora da Cola, Ourique (Beja); Mondim da Beira, Tarouca [a) según S. Da Ponte (2), J. R. Carreira (3) y J. Carrasco (5); y b) según J. R. Carreira (4) y J. Carrasco (6)]; 7. Monte Airoso, Granja (Penedoso).

como los realizados a las fíbulas portuguesas de Mondim da Beira y a la sevillana de El Coronil, no conocemos la tradición en este tipo de investigaciones de los laboratorios que las realizaron, especialmente las primeras, por lo que sería necesario contrastarlo.

De las catorce fibulas analizadas, algunas de ellas como la denominada sícula de Huelva, primera de Monachil, Cerro Alcalá, El Coronil, Canto Tortoso y las dos de Mondim da Beira, ya fueron objeto de comentarios en trabajos globales anteriores, realizados sobre la metalurgia de las antiguas fíbulas de codo peninsulares (Carrasco et alii, 1999 y 2005). En esta ocasión, solo las contrastaremos con las nuevas analíticas obtenidas exclusivamente en casos de las del tipo Monachil y sólo a partir de consideraciones generales.

Una observación rápida del cuadro de composición metalográfica de los elementos de las fíbulas (Fig. 5), elaborado con los datos de los catorce ejemplares analizados, sugiere algunas conclusiones inmediatas. Doce de ellas presentan una aleación binaria de cobre y estaño $(\mathrm{Cu} / \mathrm{Sn})$, una con una posible aleación ternaria, al contener también hierro $(\mathrm{Cu} / \mathrm{Sn} / \mathrm{Fe})$ y otra fundida en $\mathrm{Cu}$ puro, o aleada con arsénico (As). De las binarias, cinco presentan porcentajes de Sn medio/bajo 
(Monachil 1 y 2, Canto Tortoso, Cerro Alcalá, Peña Negra 1), correspondiendo a ejemplares de Andalucía Oriental y Levante, de puente con brazos básicamente filiformes y sección fina ligeramente oblonga, aunque la de Cerro Alcalá es ligeramente fusiforme. Cinco lo tienen medio/alto (Ría, Agujetas, Concejiles 1 y 2 y Peña Negra 2), en fíbulas fusiformes de amplia sección circular u oblonga, de las llamadas de «brazos amorcillados» por Almagro Basch y dos alto (Mondim da Beira 1 y 2), en ejemplares de brazos decorados con gruesas secciones oblongas. A la fíbula $n^{\circ} 1$ de Peña Negra, por distintos motivos, se le han realizados tres análisis. Primero, por su mineralización y el análisis obtenido de un pulido, no de pátina, puede ofrecer una ligera distorsión; segundo, por su bajo contenido de Sn, motivado quizá por un reciclado del metal. La evidencia de la metalurgia presente en Peña Negra indica una fundición local que no aclara suficientemente el problema anterior. En todo caso, esta fíbula por tipología es más antigua que la $\mathrm{n}^{\mathrm{o}} 2$ del yacimiento.

El análisis de la fíbula de El Coronil da en principio una aleación ternaria, que también puede ser resultado de una riqueza en $\mathrm{Fe}$ del mineral de $\mathrm{Cu}$ fundido para su elaboración. Aunque, a priori, nos inclinaríamos por una aleación intencionada de $\mathrm{Fe}, \mathrm{Cu}$ y Sn. Entraría dentro de las denominadas fusiformes, con brazos amorcillados. Por último, la fíbula fundida en $\mathrm{Cu}$ puro, arsenicado o aleado con As, procedente de Las Muelas, es la que a nuestro juicio presenta el máximo interés; no sólo entre las del tipo Monachil que hemos descrito, sino entre todo el conjunto de las de codo antiguas, dentro y fuera de la Península. En teoría, por $\mathrm{XRF}$, tiene una aleación $\mathrm{Cu} / \mathrm{As} \mathrm{y}$, por ICP sin rastrearse el As, presenta un $\mathrm{Cu}$ con ínfimos oligoelementostraza. No pondremos excesivo énfasis en la aleación de esta fíbula, objeto actualmente de un estudio más detallado. Solo indicar que no tiene parangón con ninguna otra conocida del Bronce Final peninsular y sí, por el contrario, muy relacionada con la que presentan los bronces argáricos tardíos. Lo que no indica, por motivos obvios, que consideremos esta fíbula argárica, pero sí con cronología arcaica, si no la más arcaica, entre las que más dentro del conjunto de las de codo.

Desde las generalidades expresadas y siguiendo parámetros no coyunturales, ya expuestos en un trabajo anterior (Carrasco et alii, 1999), como recientemente se ha expresado sin ninguna argumentación (Vilaça et alii, 2012), volvemos a insistir en el hecho contrastado de que en el desarrollo de la metalurgia antigua en la Península Ibérica se dieron, al menos, tres procesos tecnológicos correlativos en las técnicas de fundición del metal: cobre puro, cobre con arsénico y bronce (cobre y estaño). Los dos primeros pasos aparecen relativamente bien precisados, salvo casos puntuales que necesitarían estudios pormenorizados de cronología, más que de tipología, en la Prehistoria del Sureste; pero el tercero, que coincidiría con la plena metalurgia del bronce, y que se situaría cronológica y culturalmente en el tránsito del Bronce Final y su desarrollo posterior, ofrecería más dificultades.

\begin{tabular}{|c|c|c|c|c|c|c|c|c|c|c|}
\hline Análisis & Yacimiento & $\mathrm{Fe}$ & $\mathrm{Ni}$ & $\mathrm{Cu}$ & $\mathrm{Zn}$ & As & $\mathrm{Ag}$ & Sn & $\mathrm{Sb}$ & $\mathrm{Pb}$ \\
\hline \multirow[t]{4}{*}{ AA 0406} & Ría de Huelva & 0,21 & 0,05 & 85,88 & - & nd & 0,008 & 13,61 & nd & nd \\
\hline & El Coronil & 3,43 & 0,54 & 77,9 & 0,004 & nd & - & 16,9 & 0,28 & 0,49 \\
\hline & Monachil 1 & 0,012 & 0,106 & 91,2 & 0,008 & 0,21 & .046 & 6,86 & .06 & .088 \\
\hline & Monachil 2 & - & - & 93,5 & - & nd & - & 6,3 & - & nd \\
\hline PA20254 & C. Agujetas & 0,14 & nd & 87,9 & nd & nd & nd & 11,9 & nd & $\operatorname{tr}$ \\
\hline \multirow[t]{2}{*}{ STGR-1 } & $\begin{array}{l}\text { Canto Tortoso (XRF) } \\
\text { Canto Tortoso (ICP) }\end{array}$ & 0,011 & $\begin{array}{l}- \\
0,064\end{array}$ & $\begin{array}{l}93,5 \\
92,709\end{array}$ & - & $\begin{array}{l}\text { nd } \\
0,142\end{array}$ & 0.050 & $\begin{array}{l}6,4 \\
6,433\end{array}$ & - & $\begin{array}{l}\text { nd } \\
0,492\end{array}$ \\
\hline & $\begin{array}{l}\text { Las Muelas (XRF) } \\
\text { Las Muelas (ICP) }\end{array}$ & 0,22 & 0,001 & $\begin{array}{l}98,5 \\
99,2\end{array}$ & 0,028 & $\begin{array}{l}1,5 \\
==\end{array}$ & 0,008 & 0,002 & 0,004 & nd \\
\hline SBA-516 & Cerro Alcalá & 0,017 & 0,471 & 90,3 & 0,008 & 0,16 & 0,015 & 6,28 & 0,07 & 0,218 \\
\hline PA21874 & Peña Negra 1 PN.13920 & 0.12 & Nd. & 97.07 & Nd. & 0.07 & Nd. & 2,74 & Nd. & Nd. \\
\hline PA21874A & Peña Negra 1 PN.13920 & 0,45 & Nd. & 96,9 & Nd. & 0,12 & & 2,33 & Nd. & 0,18 \\
\hline PA21874B & Peña Negra 1 PN.13920 & 0,13 & Nd. & 96,5 & $\mathrm{Nd}$ & 0,09 & & 3,25 & Nd. & 0,06 \\
\hline PA21873 & Peña Negra 2 PN-13919 & Nd. & Nd. & 89,62 & Nd. & 0.06 & Nd. & 10,32 & Nd. & Nd. \\
\hline PA11346 & Los Concejiles 1 & 0,45 & nd & 85,9 & nd & nd & nd & 13,6 & nd & 0,04 \\
\hline PA11354 & Los Concejiles & 0,60 & nd & 88,43 & nd & 0,17 & nd & 10,8 & nd & $\mathrm{Nd}$ \\
\hline $\mathrm{MB} / 1$ & $\begin{array}{l}\text { 1.Mondim da Beira } \\
\text { Mondim da Beira }\end{array}$ & Vest. & & $\begin{array}{l}51,39 \\
53,11\end{array}$ & & & & $\begin{array}{l}48,60 \\
46,89\end{array}$ & & \\
\hline $\mathrm{MB} / 2$ & $\begin{array}{l}\text { 2.Mondim da Beira } \\
\text { Mondim da Beira }\end{array}$ & Vest. & & $\begin{array}{l}75,97 \\
67,02\end{array}$ & & & & $\begin{array}{l}24,03 \\
32,08\end{array}$ & & \\
\hline
\end{tabular}

Figura 5: Cuadro de composición metalográfica. 
En reflexiones realizadas hace casi quince años (Carrasco et alii, 1999, 125), vigentes en la actualidad, señalábamos lo siguiente: «creemos que no debemos estar muy descaminados si consideramos que en el proceso de la historia de las aleaciones del bronce pudieron darse varias fases evolutivas -al margen de tradiciones locales, conservadurismos, recursos mineros propios de cada región, influencias tecnológicas exteriores, etc.- que coincidirían grosso modo con situaciones culturales dentro del Bronce Final. Desde esta perspectiva una primera fase estaría caracterizada por la inicial aparición del estaño en las aleaciones, siempre en bajos porcentajes, junto a la presencia del arsénico ya como oligoelemento más o menos importante, en lo que pudiésemos denominar fase de tanteos y que coincidiría con las postrimería del Bronce Tardío/inicios del Bronce Final en el Sureste. Una segunda fase se caracterizaría por un incremento, dentro de las aleaciones, del porcentaje de estaño, el paralelo decrecimiento del cobre y la práctica desaparición del arsénico, en lo que podríamos llamar fase de consolidación, coincidiendo con un Bronce Final Pleno. Por último, una tercera fase caracterizada por bronces más evolucionados y tardios, que presentan aleaciones con grandes volúmenes de estaño, a veces fuertes porcentajes de plomo y otras de hierro, constituyendo en muchos casos claras aleaciones ternarias y de otro tipo, que definiría una fase final de tal metalurgia, relacionada en muchos aspectos con los últimos momentos del Bronce Final/inicios del Hierro».

Desde esta perspectiva, en su momento novedosa para este tipo de estudios y hasta la fecha no revisada ni actualizada, podemos configurar grupos concretos de fíbulas, siempre del tipo Monachil, con ciertas semejanzas en sus aleaciones, que podrían relacionarse con factibles secuencias tipológicas/cronológicas y que, a falta de otro tipo de argumentaciones más precisas, pueden ayudarnos de momento a contextualizarlas por sí mismas, al margen de posteriores precisiones.

Previo, o en los inicios de lo que hemos denominado fase de tanteos, debería situarse el ejemplar granadino de Las Muelas (A). Es evidente que en su aleación, el mineral de $\mathrm{Cu}$ en que fue fundida no coincide con ningún momento tecnológico de la fase de tanteos, pues taxativamente responde a una composición propia de momentos epigonales argáricos. Los análisis más específicos que se le han realizado no indican refundiciones, ni nada similar, sino más bien que procede de un taller local con mineral fundente obtenido en la misma región. De igual forma, la tecnología empleada para su elaboración final es la más simple que hemos documentado, no sólo para las del tipo $\mathrm{Mo}$ nachil, sino para todas las que en general conforman el elenco fibular de codo antiguo. Se realizó a partir de un fino hilo de sección casi cuadrangular, martilleado en los brazos del puente y la mortaja, terminando con un limado profundo y pulido en la aguja y el codo centrado, que está inclinado sin precisión sobre el brazo izquierdo. En la tabla tipológica que hemos elaborado (Fig. 6) ocuparía por tipología, elaboración y metal en que se fundió, el primer lugar de la serie. Sin duda estaría en el origen, al menos, de todo el conjunto fibular de codo estudiado en la Península Ibérica, por no hacerlo extensible a otros ámbitos mediterráneos. Iniciaría o estaría cronológicamente por encima del Grupo A, primero de nuestra secuencia crono-tipológica y recibiría una datación que, con precaución, no debería bajar a priori del siglo XIII a.C., aunque no descartaríamos que la sobrepasase en ambos sentidos.

A continuación, el grueso de las fíbulas que componen este primer grupo lo compondría la segunda y primera de Monachil, seguido de la de Canto Tortoso, en el orden citado, que podríamos denominar $\mathbf{A 1}, \mathbf{A 2}$ y A3. Las tres entrarían de pleno en la fase que hemos denominado de tanteos, con aleaciones medias bajas en Sn y As como oligoelemento general. Las tres, siguiendo parámetros del ejemplar de Las Muelas, tienen perfil de triángulo isósceles bajo, aunque paulatinamente van desarrollando altura, con un codo cada vez más vertical. También se comprueba en planta que los brazos del puente van desarrollando un perfil cada vez más fusiforme, para posteriormente poder desarrollar en ellos algún tipo de decoración visible. Aunque ya en la primera fíbula de Monachil se comprueba una sucinta decoración de fajas buriladas. Este grupo tendría una cronología aproximada entre el siglo XII y la primera mitad del XI a.C., que es cuando posiblemente entren en escena las primeras fibulas del grupo Huelva y, quizás, algún ejemplar del tipo ad occhio.

En un segundo grupo que denominamos $\mathbf{B}$, tendrían cabida los dos ejemplares de La Muralla de Valdehúncar. Presentan un modelo similar a las del grupo A, diferenciado sólo por sus dimensiones algo mayores y los brazos del puente más filiformes y aplanados, donde desarrollar motivos decorativos incisos. Como así ocurre en la B1, con motivos aislados de fajas compuestas por incisiones paralelas que delimitan el codo; en la B2 hay desarrollos decorativos más complejos, de fajas con líneas incisas paralelas que engloban motivos de espigas quebradas. Las fíbulas de este grupo $\mathbf{B}$, como el anterior A, no están elaboradas o fundidas en molde, sino a partir de una varilla, posiblemente desgajada o cortada de una placa, que posteriormente fue configurada con forja y lima. La cronología de este grupo, grosso modo, encajaría entre la segunda mitad del s. XI y la primera del X a.C.

Un tercer grupo, que denominamos $\mathbf{C}$, acogería un conjunto algo más amplio de fíbulas y con más problemas de filiación. En él entrarían ejemplares que consideramos se fundieron en molde y a la cera perdida, de sección gruesa, claramente fusiformes y decoraciones complejas, invasoras e intensas a lo largo y ancho de los brazos del puente. Aquí podríamos incluir, por características morfo-tipológicas, las fíbulas de Cerro Alcalá (C1), Talavera la Vieja (C2) y quizás Monte Airoso (C3), las dos de Los Concejiles (C4 y C5) y el fragmento de brazo de Peña Negra (C6), como 

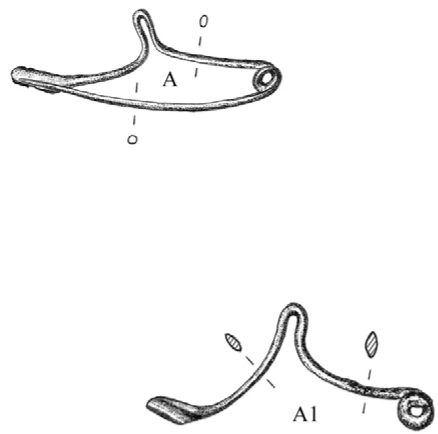

S. XII a.C.
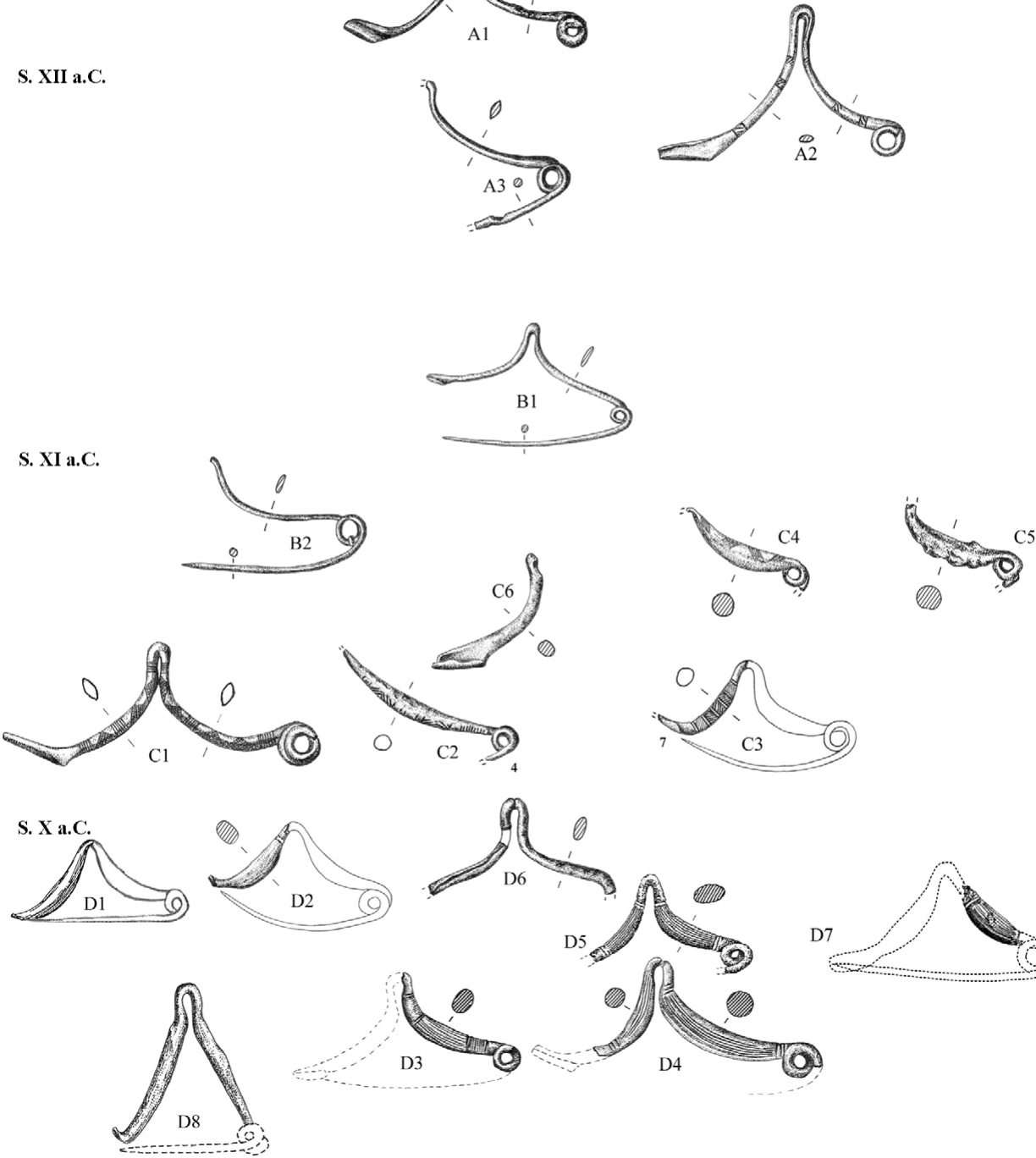

D7

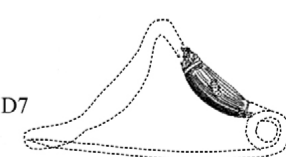

S. IX a.C.

Figura 6: Fíbulas 'sículas' de tipo Monachil. Tabla crono-tipológica. Las Muelas (A); Cerro de la Encina (A1 y A2); Canto Tortoso (A3); La Muralla (B1 y B2); Cerro Alcalá (C1); Talavera de la Reina (C2); Monte Airoso (C3); Los Concejiles (C4 y C5); La Peña Negra (C6 y D6); Ría de Huelva (D1); Las Agujetas (D2); Mondim da Beira (D3 y D4); El Coronil (D5); Nossa Senhora da Cola (D7) y Mansilla de Mulas (D8).

ejemplares más evolucionados, que también podrían entrar en el siguiente grupo. Posiblemente, el ejemplar de Cerro Alcalá sea el más controvertido, pues presenta un porcentaje de $\mathrm{Sn}$ medio bajo y una configuración y planta que podría entrar en grupos anteriores. Pero su contexto arqueológico, único que lo tiene de este grupo, encaja mejor entre la segunda mitad del s. X y la primera del IX a.C. Cronología que consideramos aceptable para el resto fibular del grupo $\mathbf{C}$.
Un último grupo, que denominamos $\mathbf{D}$, lo compondrían fíbulas globulosas, con grandes cantidades de $\mathrm{Sn}$, a veces fundidas en aleaciones ternarias, en las que se usaron técnicas sofisticadas como el taladro continuo. A veces, presentan finos diseños decorativos simples de trazos paralelos, que recorren las superficies inferiores o superiores de los brazos del puente. Es difícil seguir la trayectoria tipológica de estas piezas, pues en el fondo responden a exigencias muy 
locales. Entre ellas, básicamente, podríamos destacar las procedentes de la Ría (D1), Cerro de las Agujetas (D2), las dos de Mondim da Beira (D3 y D4), El Coronil (D5), quizás la más completa de La Peña Negra (D6), Nossa Senhora da Cola (D7) y la de Mansilla de Mulas (D8), pieza última, posiblemente retardataria de otras formas más antiguas. La cronología de todas ellas, puede situarse en el siglo IX, especialmente a partir de su segunda mitad, sin descartar pervivencias más tardías, incluso de la primera mitad del VIII a.C.

En este conjunto disperso, que hemos intentado sistematizar, entrarían las fíbulas del Cerro de la Mora, que se insertarían a lo largo de la seudo secuencia elaborada, destacando que en ninguna de ellas se han observado decoraciones incisas o de otro tipo. Aunque es posible, que por su mal estado de conservación, hayan desaparecido sin que fuese posible su documentación.

\section{DISCUSIÓN Y CONCLUSIONES}

A partir de registros descontextualizados, junto a otros aún no estudiados, por primera vez hemos intentado de forma rápida y sin complejizar, sistematizar y reordenar un conjunto de fíbulas españolas que, tradicionalmente, entrarían dentro del periclitado taxón sículo y que, por nuestra parte, para diferenciarlas del resto de este gran grupo, hemos denominado desde hace años, más adecuadamente, tipo Monachil. Estamos esperanzados en que esta pequeña elaboración sea capaz de abrir, en los próximos años, debates sobre el tema. Con independencia de la oportunidad que esto les merezca a unos u otros investigadores, esperemos al menos que se reduzcan otras posiciones que, hasta ahora, por falta de más adecuados argumentos, han venido globalizando estas fíbulas y confundiéndolas en un totum revolutum engañoso. En ocasiones, con la única y exclusiva finalidad de justificar su presencia en un impreciso comercio de la Península, relacionado con ciertos ambientes sículos del Mediterráneo Central.

Desde los estudios de Almagro Basch, sobre los bronces de la Ría de Huelva, la famosa fíbula sícula fue mal interpretada y reconstruida como modelo de puente disimétrico, para asimilarla con otros modelos sicilianos que presentaban esta característica. Esta errónea interpretación tuvo una fuerte incidencia en todos los trabajos posteriores realizados sobre restos fibulares, pues sin plantearse ningún tipo de dudas fueron reinterpretadas de similar forma que la del ejemplar de la Ría, estableciendo sin originalidad los mismos paralelos disimétricos sicilianos, que los propuestos por Almagro hace más de cincuenta años. La realidad, como se analizó en un trabajo reciente (Carrasco et alii, 2012), es que la fíbula de la Ría debió tener un codo centrado, una simple rectificación que daría al traste con la intensa literatura peninsular vertida sobre su llegada desde Sicilia.

De nuestro tipo Monachil se documentan cuatro ejemplares con ciertas similitudes en hallazgos realizados en las necrópolis sicilianas, todas de codo centrado. Procedente de Castelluccio, Ragusa (GiumliaMair et alii, 2010, Fig. 11), clasificada con el tipo 290.2 (5279 B) (Lo Schiavo, 2010, 604, Tavola 368, 5279b), se documenta una pequeña fíbula sin mortaja, que tendría el codo centrado y el puente con decoración similar a la de El Coronil, fechada en el BF $3 / \mathrm{I}^{\circ} \mathrm{Fe}$ I. De igual forma, de tres sepulturas de Cugno Spineta, que forman parte de la extensa necrópolis de Cassibile, proceden tres fíbulas de necesaria referencia (Turco, 2000). De las tumbas CS.8 y CS.28, existen sendos brazos «amorcillados» de dos fíbulas, catalogadas como del Tipo $15 \mathrm{~B}$, que presentan el codo centrado. Aunque de mayores dimensiones, tienen características muy similares a las de la Ría y Cerro de las Agujetas y con alguna otra de las descritas en nuestro tipo Monachil. Por último, en la tumba CS.5, apareció una tercera fíbula englobada en el Tipo 17b, de características distintas a las dos anteriores y muy similar por el perfil al ejemplar antiguo de Las Muelas. Aunque el codo de la italiana está algo descentrado, mientras su elaboración se hizo a partir de una amplia pletina de sección rectangular de $0,8 \times 0,2$ $\mathrm{cm}$. Existen otros tres ejemplares de las tumbas CS.83, CS.84 y CS.99 (Turco, 2000) que, por su decoración, pueden tener ciertas similitudes con las constatadas en fíbulas peninsulares, como la de Monte Airoso, Talavera la Vieja, etc., pero que, al presentar un claro puente disimétrico, se alejan del tipo Monachil.

En resumen, no se comprueban similitudes morfométricas entre las fíbulas sículas y las de tipo $\mathrm{Mo}$ nachil, existiendo la paradoja de que las dos únicas fíbulas italianas de las tumbas CS.8 y CS.28, con cierto parecido a la lisa de la Ría, presentan el codo centrado, como igualmente hemos destacado para ésta en nuestra reconstrucción. Del mismo modo, la cronología que presentan estas fíbulas en las necrópolis de Cassibile corresponde a una fase avanzada de Pantalica II (B), incluso de Pantalica III, desde la primera mitad del siglo IX hasta el VIII a.C., similar a la que ofrecemos para algunas de las españolas tardías. Se comprueba cómo en la secuencia de fíbulas italianas, las más antiguas que podrían corresponder a Pantalica I, por encima del s. XI, son todas de violín y arco simple y es a partir del año 1000 a.C. cuando existe una cierta diversificación, dentro de este mismo modelo que sigue predominando en Pantalica IIA en el siglo XI-X. A partir de la segunda mitad del X y primera del IX, correspondiente a Pantalica IIB, es cuando se produce una diversificación de tipos y un cambio radical, en relación con el tipo de arco simple y evoluciones, gracias a la aparición de una amplia gama de fíbulas con codo descentrado y del modelo ad occhio.

Por el contrario, las fíbulas españolas, de perfiles en forma de triángulo isósceles, secciones de puente más simples y codo centrado, características ya descritas para nuestro grupo A, son totalmente diferentes de las italianas y, quizás en algún caso, con mayor cronología que éstas. A continuación, en las fíbulas de los siguientes grupos (B, C y D) no existe una ruptura 
clara con las del modelo A, pero sí variaciones respecto de él, aunque siempre con el codo centrado. Por el contrario, las italianas sufren cesuras y evoluciones difíciles de captar, junto con cronologías estimativas más recientes que las españolas. Al respecto, solamente indicar que la fíbula de codo descentrado de Las Lunas (Yúncler, Toledo), que datábamos a mediados del siglo X a.C. (Carrasco et alii, 2012), ha sido recientemente fechada por C14 hacia el 950 a.C. (Urbina y Garcia, 2010), fecha que sería impensable -por antigua- para similares, aunque no iguales, modelos italianos. Las mismas ad occhio peninsulares, todas de bucle centrado, especialmente las de Soto de Tobilla y Perales del Rio, tendrían una cronología anterior a las de bucle descentrado italianas, no solamente por sus características morfo-tipológicas, sino por el contexto cultural en que aparecieron. En definitiva, de ningún modo puede justificarse actualmente la presencia del grupo Monachil en la Península Ibérica por un comercio o llegada de poblaciones desde el Mediterráneo Central.

Pero, si no llegan desde estos ambientes sículos, ¿podríamos preguntarnos sobre otras procedencias más factibles? En principio no consideramos, en ningún caso, las sugerencias de C. Blasco, siguiendo a J. Fernández Manzano, de que estas fíbulas lisas fuesen, en último lugar, una derivación tardía por evolución, a través de un «proceso de simplificación», de las del tipo Huelva. Cuestión que, por manifiesta inviabilidad, no propicia ningún tipo de polémica o comentario. En este punto, podríamos intentar asimilarlas a los archiconocidos modelos orientales, que en principio no consideraremos en el origen de las del tipo Monachil; aunque, a nivel morfométrico, hay ciertas similitudes que pueden ser resaltadas, pero que en nuestra opinión son escasamente determinantes. Un punto de unión entre ellas es que todas presentan el codo centrado, como sucede en la antigua fíbula de Kourion en la Colección Cesnola, Megiddo Va, Amathus 243, 523, etc. De igual forma, todas presentan un perfil alto en forma de triángulo isósceles, similar a las de tipo Monachil; sin embargo, en estas fíbulas orientales los brazos del puente están moldurados, lo que las aleja decisivamente de las lisas peninsulares: al margen de que aquí la cronología es sensiblemente más antigua. Podríamos mencionar el ejemplar liso de Lefkandi (Carrasco y Pachón, 2006c) procedente de la isla griega de Euboia, pero es de perfil bajo, realizada en una amplia pletina de oro con codo centrado y una cronología más reciente, recordando alguna elaboración sícula tardía, como la fíbula documentada en la tumba CS.54 de Cugno Spineta de Cassibile.

En definitiva, podemos concluir que particularmente no conocemos ningún modelo fibular fuera de la Península Ibérica que se aproxime, o podamos entroncar de forma nítida con las de tipo Monachil. Desde este punto de vista, no tenemos posibilidad alguna para establecer relaciones de ningún tipo con ejemplares de ida y vuelta, en el Mediterráneo Central u Oriental. Cuestión que con excesiva imaginación sería posible, sin total seguri$\mathrm{dad}$, con algunos casos peninsulares tardíos del tipo $\mathrm{ad}$ occhio, o incluso con algunos otros de arco descentrado y violín de procedencia desconocida, como la del SIP de Valencia y la publicada por G. Delibes (1981) sobre dibujo antiguo, supuestamente del Berrueco; aunque no sabemos, si llegadas en un tipo de comercio moderno o antiguo. Así, sin conocer paralelos extrapeninsulares para el tipo Monachil, debemos concluir sopesando la autoctonía de estas fíbulas en la Península Ibérica, quedándose en el camino, como se ha expuesto, la extensa literatura vertida sobre su origen o entronque foráneo, especialmente con los ejemplares sículos. Algo que no es de extrañar, si consideramos en las peninsulares su cronología más antigua, tecnología arcaica y configuración única. Sin olvidar que conforman un grupo homogéneo, relativamente amplio y único, en su mayoría procedentes de contextos probablemente habitacionales.

Prof. Dr. Javier Carrasco Rus
Dr. Juan A. Pachón Romero
Dr. Jesús Gámiz Jiménez
Dpto. de Prehistoria y Arqueología
Facultad de Filosofía y Letras
Campus de Cartuja
Universidad de Granada
18071 Granada
jcrus@ugr.es
japr@arrakis.es
gamizjimenez@gmail.com
Dr. Ignacio Montero Ruiz
Instituto de Historia
Centro de Ciencias Humanas y Sociales - CSIC
c/ Albasanz, 26-28
28037 Madrid
ignacio.montero@cchs.csic.es
Prof. Dr. Alfredo González Prats
Área de Prehistoria
Dpto. Prehistoria, Arqueología, HanAntigua, Fil. Griega y
Fil. Latina
Universidad de Alicante
Apdo. Correos 99
03080 Alicante
alfredo.gonzalez@ua.es

\section{BIBLIOGRAFÍA}

ALMAGRO BASCH, M., 1940a: «El hallazgo de la Ría de Huelva y el final de la Edad del Bronce en el Occidente de Europa», Ampurias, 2: 85-143.

ALMAGRO BASCH, M., 1940b: «La cronología de las fíbulas españolas de codo». Saitabi, 1.2, 1-5.

ALMAGRO BASCH, M., 1952: «La invasión céltica en España», en R. MENÉNDEZ PIDAL, Historia de España, I2, 1-278, Madrid.

ALMAGRO BASCH, M., 1957: «La fíbula de codo de la Ría de Huelva. Su origen y cronología», Cuadernos de la Escuela Española de Roma, IX, 7-45.

ALMAGRO BASCH, M., 1957-58: «A propósito de la fecha de las fíbulas de Huelva», Ampurias, XIX, 198-207. ALMAGRO BASCH, M., 1958: Depósito de la Ría de Huel$v a$. Inventaria Arqueológica. España, 1-4: E. 1, Madrid.

ALMAGRO BASCH, M., 1966: Las estelas decoradas del Suroeste Peninsular, BPH VIII, Madrid. 
ALMAGRO BASCH, M., 1975: «Depósito de bronces de la Ría de Huelva», Huelva, Prehistoria y Antigüedad, 213-220, Madrid.

ARRIBAS PALAU, A., PAREJA LÓPEZ, E., MOLINA GONZÁlEZ, F., ARTEAGA MATUTE, O. y MOLINA FAJARDO, F., 1974: Excavaciones en el poblado de la Edad del Bronce «Cerro de la Encina» Monachil (Granada) (El corte estratigráfico $n^{\circ} 3$ ), Excavaciones Arqueológicas en España 81, Madrid.

BARROSO BERMEJO, R. y GONZÁLEZ CORDERO, A. 2007: «Datos para la definición del Bronce Final en la zona suroccidental de la Meseta. Los yacimientos de la Comarca del Campo Arañuelo (Cáceres)», Revista de Estudios Extremeños, 63, 1, 11-36.

BLASCO BOSQUED, M C., 1987: «Un ejemplar de fíbula de codo 'ad occhio' en el Valle del Manzanares», BAEAA, 23, 18-28.

BRUINS, H.J., NIJBOER, A.J. y PLICT, J. van der, 2011: «Iron Age Mediterranean chronology: a reply», Radiocarbon, 53 (1), 199-220.

BUCHHOLZ, H.G., 1986: «Ein kyprischer Fibeltypus und seine auswartige Verbreitung», Cyprus Berween the Orient and the Occident, Acts of the Internacional Archaeologycal Symposium, Nicosia, 8-14 sept. (1985), 223-245, Nicosia.

CABRÉ AGUILÓ, J., 1922: «Una necrópolis de la primera Edad de los Metales», Actas de la Sociedad Española de Antropología, Etnografia y Prehistoria, 23-36.

CARDOSO, J. L., 2002: Pré-História de Portugal, Lisboa.

CARRASCO RUS, J. y PACHÓN ROMERO, J.A., 1998a: «La fíbula de codo tipo Huelva procedente de la comarca de Puerto Lope/Íllora (Granada)», Tomás Quesada Quesada. Homenaje, 877-896, Granada.

CARRASCO RUS, J. y PACHÓN ROMERO, J.A., 1998b: «Fíbulas de codo tipo Huelva de Montejícar, Granada», Florentia Iliberritana, 9, 423-444.

CARRASCO RUS, J. y PACHÓN ROMERO, J.A., 2001: «Fíbula de codo tipo Huelva en el entorno norte de la Vega de Granada», Spal, 10, 235-248.

CARRASCO RUS, J. y PACHÓN ROMERO, J.A., 2002: «Fíbulas de codo en las altiplanicies granadinas: dos nuevos hallazgos en la comarca de Guadix», Tabona, 11, 169-188.

CARRASCO RUS, J. y PACHÓN ROMERO, J.A., 2004: «Fíbulas de codo de tipo Huelva en la Provincia de Granada», Revista del Centro de Estudios Históricos de Granada y su Reino, 16, 13-69.

CARRASCO RUS, J. y PACHÓN ROMERO, J.A., 2006a: «Sobre la cronología de las fíbulas de codo tipo Huelva», Archivo de Prehistoria Levantina, XXVI, 245-292.

CARRASCO RUS, J. y PACHÓN ROMERO, J.A., 2006b: «La fíbula de codo tipo Huelva. Una aproximación a su tipología», Complutum, 17, 103-119.

CARRASCO RUS, J. y PACHÓN ROMERO, J.A., 2006c: «Algunas cuestiones sobre el origen oriental de la fíbula de codo tipo Huelva», Revista Tabona, 14, 63-92.

CARRASCO RUS, J., PACHÓN ROMERO, J.A., ADROHER AUROUX, A. y LÓPEZ MARCOS, A., 2002: «Taller metalúrgico de fines del bronce en Guadix
(Granada): contribución a la contextualización de las fíbulas de codo tipo Huelva en Andalucía Oriental», Florentia Iliberritana, 13, 357-385.

CARRASCO RUS, J., PACHÓN ROMERO, J.A. y ESQUIVEL GUERRERO, J.A., 2005: «Nuevos datos para el estudio metalúrgico de la fíbula de codo tipo Huelva», Homenaje J. Smolka Cláres, Universidad de Granada, 21-40.

CARRASCO RUS, J., PACHÓN ROMERO, J.A., ESQUIVEL GUERRERO, J.A. y ARANDA JIMÉNEZ, G., 1999: «Clasificación secuencial tecno-tipológica de las fíbulas de codo de la Península Ibérica», Complutum, 10, 123-142.

CARRASCO RUS, J., PACHÓN ROMERO, J.A. y LARA, I., 1980: «Hallazgos del Bronce Final en la provincia de Jaén. La necrópolis de Cerro Alcalá, Torres (Jaén) », CPUGr, 5, 221-36.

CARRASCO RUS, J., PACHÓN ROMERO, J.A., MONTERO-RUIZ. I. y GÁMIZ JIMÉNEZ, J., 2012: «Fíbulas de codo 'tipo Huelva' en la Península Ibérica: nuevos datos y comentarios historiográficos», Trabajos de Prehistoria, 69:2, 141-162.

CARRASCO RUS, J., PACHÓN ROMERO, J. A. y PASTOR MUÑOZ, M., 1985: «Nuevos hallazgos en el conjunto arqueológico del Cerro de la Mora. La espada de lengua de carpa y la fíbula de codo del Cerro de la Miel (Moraleda de Zafayona, Granada) », CPUGr, 10, 265-333.

CARRASCO RUS, J., PACHÓN ROMERO, J. A., PASTOR MUÑOZ, M. y GÁMIZ JIMÉNEZ, J., 1987: La espada de lengua de carpa del Cerro de la Miel (Moraleda de Zafayona) y su contexto arqueológico. Nuevas aportaciones para el conocimiento de la metalurgia del Bronce Final en el sudeste peninsular, Moraleda de Zafayona.

CARREIRA, J. R., 1994: «A Pré-História Recente do Abrigo Grande das Bocas (Rio Maior)», Trabalhos de Arqueologia da EAM, 2, 47-144.

CELESTINO PÉREZ, S., 2001: Estelas de guerreros y estelas diademadas. La precolonización y formación del mundo tartésico, Bellaterra Arqueología, Barcelona.

CELESTINO PÉREZ, S., 2008: «La precolonización a través de los símbolos», en S. CELESTINO, N. RAFEL, y L. ARMADA (Eds.), Contacto cultural entre el mediterráneo y el atlántico (siglos XII-VIII ane). La precolonización a debate, Escuela Española de Historia y Arqueología en Roma, CSIC. Serie Arqueológica 11, 107-119, Madrid.

DELIBES DE CASTRO, G., 1981: «Una interesante fíbula del Bronce Final del Cerro del Berrueco (Salamanca)», Guimarâes, XVI, 172-182.

GIUMILIA-MAIR, A., ALBANESE, R. M. y LO SCHIAVO, F., 2010: «The Metallurgy of the Sicilian Final Bronze Age/Early Iron Age necropolis of Madonna del Piano (Catania, Sicily)», Trabajos de Prehistoria, 67:2, 469-488.

GONZÁLEZ PRATS, A., 1992: «Una vivienda metalúrgica en la Peña Negra (Crevillente-Alicante). Aportación al conocimiento del Bronce Atlántico en la Península Ibérica», Trabajos de Prehistoria, 49, 243-257. 
GONZÁLEZ PRATS, A., 2002: La necrópolis de cremación de Les Moreres (Crevillente, Alicante, España) (s. IXVII AC), Alicante.

GONZÁlEZ ROMÁN., C., ADROHER AUROUX, A. y LÓPEZ MARCOS, A., 1995: «El yacimiento de Canto Tortoso (Gorafe, Granada): Un enclave comercial del siglo VI a.C. em el Guadiana Menor», Verdolay, 7, 150-176.

HOOK, D.R., ARRIBAS PALAU, A., CRADDOCK, P.T., MOLINA GONZÁLEZ, F. y ROTHENBERG, B., 1987: «Copper and Silver in Bronce Age Spain», BAR Internacional Series 331 (I), 147-172.

JIMÉNEZ ÁVILA, J. y GONZÁLEZ CORDERO. A., 1999: «Referencias culturales en la definición del Bronce Final y la Primera Edad del Hierro de la Cuenca del Tajo: el yacimiento de Talavera la Vieja, Cáceres», II Cong. Arq. Peninsular, III. Primer Milenio y Metodología, 181-190, Madrid.

LEITE DE VASCONCELOS, J., 1933: Memorias de Mondim da Beira, Impresa Nacional, Lisboa.

LO SCHIAVO, F., 2010: Le Fibule dell'Italia meridionale e della Sicilia dall'età del bronzo recenté al VI secolo a.C, Prähistorische Bronzefunde, XIV, 14, Band, Teil 1-3, Mainz.

MEDEROS MARTÍN, A., 1996: «La conexión LevantinoChipriota. Indicios de comercio Atlántico con el Mediterráneo Oriental durante el Bronce Final (1150-950 a.C.)», Trabajos de Prehistoria, 53:2, 95-115.

MOLINA GONZÁLEZ, F. 1977: La cultura del Bronce Final en el Sudeste de la Península Ibérica. Resúmenes de Tesis Doctorales de la Universidad de Granada, 178, Granada.

MOLINA GONZÁLEZ, F., 1978: «Definición y sistematización del Bronce Tardío y Final en el Sudeste de la península Ibérica», $C P U G r, 3,159-233$.

PACHÓN ROMERO, J.A. y CARRASCO RUS, J., 2009: «Las espuelas de jinetes ibéricas en Andalucía Oriental. El ejemplar del Cerro de las Agujetas, Pinos Puente (Granada)», Revista del Centro de Estudios Históricos de Granada y su Reino, 21, 21-48.

PACHÓN ROMERO, J.A. y CARRASCO RUS, J., 2010: «Espuela de bronce en el Cerro de las Agujetas de Pinos Puente, Granada. Un vestigio artístico de la toréutica aplicada a la implementa de los caballeros en el mundo ibérico», Antiquitas, 22, 57-75.

PACHÓN ROMERO, J.A., CARRASCO RUS, J. y PASTOR MUÑOZ, M., 1979: «Protohistoria de la Cuenca Alta del Genil», CPUGr, 4, 295-340.

PONTE, S. da, 1986: «Una fíbula de Mondim da Beira (Viseu)», Beira Alta, XLV, fasc.1-2, 70-71.

PONTE, S. da, 1986b: «Valor residual de Seis fíbulas de Regiao de Beja-dimensao arqueológica e significado sócio-cultural», Arquivo de Beja, (2 ${ }^{\mathrm{a}}$ Série), nº 3, 75-87.

PONTE, S. da, 1989: «As fibulas do Bronze Final Atlántico/ $\mathrm{I}^{\mathrm{a}}$ Idade do Ferro do Noroeste Peninsular. Abordajem e encuadramento cultural», Trabalhos de Anthropologia e Etnología, 29 (1-4), 73-79.

PONTE, S. da, 2006: Corpus Signorum Das Fíbulas ProtoHistóricas e Romanas de Portugal, Casal de Cambra.
RUIZ DELGADO, M. M., 1989: Fíbulas protohistóricas en el sur de la Península Ibérica, Publicaciones de la Universidad de Sevilla 112, Sevilla.

RUIZ DELGADO, M. M., RESPALDIZA, M.A. y BARRANCO, F., 1991: «Análisis elemental de bronces arqueológicos por DRX y PIXE», Internacional Conference of Prehistory, BAR Internacional Series 573, 139163, Oxford.

RUIZ-GÁLVEZ PRIEGO, M. (Ed.), 1995: Ritos de paso y puntos de paso. La Ría de Huelva en el mundo del Bronce Final Europeo, Complutum Extra 5, Madrid.

SCHÜLE, W., 1969: Die Meseta-Kulturen der Iberischen Halbinsel. Mediterrane und eurasische Elemente in früheisenzeitlichen Kulturen Südwesteneuropas, MF, Berlin.

SHARON, I.; GILBOA, A., JULL, TAJ. y BOARETTO, E., 2007: «Report on the first stage of the Iron Age Dating Project in Israel: supporting a Low Chronology», Radiocarbon 49 (1), 1-46.

TORRES ORTIZ, M. 2002: Tartessos. Bibliotheca Archaeologica Hispana 14, Madrid.

TORRES ORTIZ, M., 2008: «Los tiempos de la precolonización», en S. CELESTINO, N. RAFEL y X. L. ARMADA, Contacto cultural entre el Mediterráneo y el Atlántico (siglos XII-VIII ane). La precolonización a debate, Escuela Española de Historia y Arqueología en Roma, Serie Arqueológica 11, 59-91, Madrid.

TORRES ORTIZ, M., 2012: «La precolonización en Extremadura», en J. JIMÉNEZ ÁVILA (Ed.), Sidereum Ana II. El rio Guadiana en el Bronce Final, Anejos de AEspA, LXII, 455-475, Madrid.

TURCO, M ${ }^{a}$ G., 2000: La necrópolis di Cassibile, Cahiers du Centre Jean Bérard XXI, Nápoles.

URBINA MARTÍNEZ, D. y GARCÍA VUELTA, O., 2010: «Las Lunas, Yuncler (Toledo). Un depósito de materiales metálicos del Bronce Final en la Submeseta Sur de la Península Ibérica», Trabajos de Prehistoria, 67:1, 175-196.

VIANA, A., 1966; Nossa Senhora da Cola. Notas históricas, arqueológicas e etnográficas do Baixo Alentejo, Arquivo de Beja 16.

VILAÇA, R., 2008: «Reflexões em torno da "presença mediterrânea" no centro do territorio portugués, na charneira do Bronze para o Ferro», en S. CELESTINO, N. RAFEL, y L. ARMADA (Eds.), Contacto cultural entre el mediterráneo y el atlántico (siglos XII-VIII ane). La precolonización a debate, Escuela Española de Historia y Arqueología en Roma, Serie Arqueológica 11, 371400, Madrid.

VILAÇA, R., JIMÉNEZ ÁVILA, J. y GALÁN DOMINGO, E., 2012: «El poblado de los Concejiles (Lobón, Badajoz) en el contexto del Bronce Final del Guadiana Menor», Anejos de AEspA, LXII, 125-165, Madrid.

VILHENA, J. y GONÇALVES, M., 2012: «A problemática de rochas vitrificadas em povoados de Bronze Final de Odomira e Ourique», Anejos de AEspA, LXII, 517-555, Madrid.

Recepción: 17-01-2013

Aceptación: 02-08-2013 